\title{
Extensive High-Resolution Synthetic Aperture Radar (SAR) Data Analysis of Tropical Cyclones: Comparisons with SFMR Flights and Best Track
}

\author{
Clement Combot, ${ }^{a}$ Alexis Mouche, ${ }^{\mathrm{a}}$ John KnafF, ${ }^{\mathrm{b}}$ Yili Zhao, ${ }^{\mathrm{a}}$ Yuan ZhaO, ${ }^{\mathrm{a}}$ Leo Vinour, ${ }^{\mathrm{a}}$ \\ YVES QUILFEN, ${ }^{\mathrm{a}}$ AND BERTRAND CHAPRON ${ }^{\mathrm{a}}$ \\ ${ }^{\text {a } L a b o r a t o i r e ~ d ' O c e ́ a n o g r a p h i e ~ P h y s i q u e ~ e t ~ S p a t i a l e, ~ I n s t i t u t ~ F r a n c ̧ a i s ~ d e ~ R e c h e r c h e ~ p o u r ~ l ' E x p l o i t a t i o n ~ d e ~ l a ~ M e r, ~ P l o u z a n e ́, ~ F r a n c e ~}$ \\ ${ }^{\mathrm{b}}$ NOAA/NESDIS Regional and Mesoscale Meteorological Branch, Fort Collins, Colorado
}

(Manuscript received 10 January 2020, in final form 22 July 2020)

\begin{abstract}
To produce more precise descriptions of air-sea exchanges under tropical cyclones (TCs), spaceborne synthetic aperture radar (SAR) instruments provide unique capabilities to probe the ocean surface conditions, at very high spatial resolution, and on synoptic scales. Using highly resolved $(3 \mathrm{~km})$ wind fields, an extensive database is constructed from RadarSat-2 and Sentinel-1 SAR acquisitions. Spanning 161 tropical cyclones, the database covers all TC intensity categories that have occurred in 5 different TC basins, and include 29 cases coincident with SFMR measurements. After locating the TC center, a specific methodology is applied to filter out areas contaminated by heavy precipitation to help extract, for each acquisition, the maximum wind speed (Vmax), its associated radius (Rmax), and corresponding outer wind radii (R34/50/64 kt). These parameters are then systematically compared with best track (BTK), and when available, SFMR airborne measurements. For collocated SFMR and SAR observations, comparisons yield root-mean-squares of $3.86 \mathrm{~m} \mathrm{~s}^{-1}$ and $3 \mathrm{~km}$ for ocean surface wind speeds and TC Rmax, respectively. High correlations remain for category-5 cases, with Vmax exceeding $60 \mathrm{~m} \mathrm{~s}^{-1}$. The largest discrepancies are found between BTK and SAR Rmax estimates, with Rmax fluctuations poorly captured by BTK, especially for rapidly evolving category-3, -4 , and -5 TCs. In heavy precipitation $\left(>35 \mathrm{~mm} \mathrm{~h}^{-1}\right)$, the SAR C-band measurements may be impacted, with local ambiguities associated with rain features, as revealed by external rain measurements. Still, this large dataset demonstrates that SAR measurements have unique high-resolution capabilities, capturing the inner- and outer-core radial structure of the TC vortex, and provide independent and complementary measurements than those used for BTK estimates.
\end{abstract}

KEYWORDS: Hurricanes/typhoons; Tropical cyclones; Wind; Algorithms; Remote sensing; Satellite observations

\section{Introduction}

Tropical cyclones (TCs) are better observed than ever before with improvements in coverage and capabilities from both remotely sensed and in situ observations. However, because of the heavy reliance of satellite-based observations in the oceanic regions where TCs form and track, creating precise descriptions of the TC surface wind field remains challenging as the necessary observations are often lacking (Knaff et al. 2016). In fact, estimates of most TC parameters including maximum sustained winds (Vmax) (Velden et al. 2006; Demuth et al. 2004) and wind radii-the radial extent of 34-, 50-, and 64-kt $\left(1 \mathrm{kt} \approx 0.51 \mathrm{~m} \mathrm{~s}^{-1}\right)$ winds (Demuth et al. 2006; Kossin et al. 2007; Knaff et al. 2011, 2016) are heavily weighted toward indirect satellite-based methods. Nonetheless, historical records or best tracks (BTK) containing TC location and intensity, and in some cases wind radii, have been compiled using such methods (Knapp et al. 2010, 2018; Landsea and Franklin 2013).

The radius of maximum wind speed (Rmax) is a critical parameter for a number of applications. It helps to locate the maximum momentum injected in the ocean when strong mixing occur (Vincent et al. 2012; Price 1981). Rmax is also an essential scaling factor for the barotropic and baroclinic ocean responses (Geisler 1970; Ginis 2002; Kudryavtsev et al. 2019a), wind model parameterization (Holland 1980; Willoughby and Rahn 2004; Wood et al. 2013; Chavas et al. 2015) and operational

Corresponding author: Alexis Mouche, alexis.mouche@ifremer.fr applications/models (Knaff et al. 2007, 2016), as well as to anticipate trapped-wave effects (Young et al. 2013; Kudryavtsev et al. 2015). Integrated kinetic energy (IKE) and wind power index (WPI) also rely on TC size information. IKE and WPI estimates were reported to outperform the sole use of Vmax estimates, to assess damages (Powell and Reinhold 2007), sea surface temperature TC wake signatures (Vincent et al. 2012), and poststorm ocean heat content capacity response (Knaff et al. 2013).

However, Rmax is often very difficult to estimate in absence of a well-defined eye feature in satellite imagery (Kossin et al. 2007; Lajoie and Walsh 2008) or aircraft reconnaissance due to the small spatial scales and strong wind gradients associated with Rmax, and the shortcomings associated with the various satellite methods (Lajoie and Walsh 2008; Knaff et al. 2011). The difficulty in estimating Rmax, likely leads to the reason why Rmax is not best tracked. Wind radii, on the other hand, are routinely used by operational centers for wave and storm surge forecasts (Sampson et al. 2010; NHC 2016), as well as the wind speed probability forecasts (DeMaria et al. 2013). In fact, since 2004, wind radii have been systematically reanalyzed for the best track at the National Hurricane Center (NHC) (Landsea and Franklin 2013). Similarly, the Joint Typhoon Warning Center (JTWC) has best track wind radii available since 2013 and in the final best tracks since 2016 (Sampson et al. 2018).

Publisher's Note: This article was revised on 17 November 2020 to correct an omission in the Acknowledgments section when originally published. 
To help in analyzing wind radii, operational scatterometers, radiometers, microwave sounders, and IR-based techniques are utilized (Sampson et al. 2017). A new generation of spaceborne instruments has recently emerged, the wide-swath L-band passive microwave sensors SMAP and SMOS (Reul et al. 2016; Meissner et al. 2017), able to estimate ocean surface wind speeds exceeding $40-50 \mathrm{~m} \mathrm{~s}^{-1}$, and also the CYGNSS constellation (Ruf et al. 2016; Morris and Ruf 2017) now assisting in that effort. Yet, while SMAP and SMOS have large swaths coverage that is ideal for estimating TC size and wind radii (Reul et al. 2017), these sensors have low spatial resolutions $(40-50 \mathrm{~km})$. This precludes precise inner-core TC descriptions. To date, only limited airborne Stepped Frequency Microwave Radiometer (SFMR) measurements provide means to probe the high wind area of hurricanes (Uhlhorn et al. 2007; Klotz and Uhlhorn 2014). In this context, numerous studies already demonstrated the potential to use satellite synthetic aperture radar (SAR) measurements to provide TC surface wind field at very high resolution (Katsaros et al. 2000; Li et al. 2013). This unique mapping capability, further supported by highly sensitive cross-polarization measurements to increasing winds, has often been highlighted with respect to SFMR (Zhang and Perrie 2012; Horstmann et al. 2015; Mouche et al. 2019), buoys (Vachon and Wolfe 2011; Zhang et al. 2012), L-band passive remote sensing measurements (Mouche et al. 2017; Zhao et al. 2018), and global models (Fang et al. 2018). Still, most of these TC studies were not based on a large number of cases, especially those cases reaching winds higher than $40 \mathrm{~m} \mathrm{~s}^{-1}$. Using collocated SFMR measurements, Mouche et al. (2019) demonstrated how combined co- and cross-polarization C-band SAR measurements, efficiently resolve TC inner-core wind field characteristics. In that study, SAR measurements sampling Hurricane Irma (2017) when it had category (CAT)-5 intensity were compared to SFMR measurements and yielded comparable ocean surface wind speeds, with bias and root-mean-square of about 1.5 and $5.0 \mathrm{~m} \mathrm{~s}^{-1}$, respectively. Retrieved wind structure parameters outside the high wind inner core were also reported to be in agreement with NHC's best track and combined satellite- and aircraft-based analyses. The Irma study showed that within the TC inner core, SAR measurements alone can provide instantaneous and independent measurements of Vmax and Rmax, even in high wind speed gradients $\left(6.5 \mathrm{~m} \mathrm{~s}^{-1} \mathrm{~km}^{-1}\right)$.

It is worth noting that contrary to most of the low-orbit Earth observation satellite missions, SAR instruments cannot continuously acquire wide swath data in high-bit rate modes. Anticipating and tasking SAR acquisitions with respect to the hurricane tracks forecast are thus required. Such tasking has been demonstrated over the past several years. In fact, since 2016, Sentinel-1 acquisition campaigns have thus been specifically designed, to test the instrument capabilities for mapping TCs (see Mouche et al. (2019) for details). A similar TC data acquisition program using RadarSat-2 was also conducted by the Canadian Space Agency (CSA) (Banal et al. 2007). Today, the combined efforts of these campaigns have provided many TC cases-strongly maximizing the utility of SAR acquisitions from both Copernicus/ESA Sentinel-1 and MDA/CSA RadarSat-2 missions.
In the present study, our main motivation is to describe how the SAR-derived wind field can be used to extract important TC parameters and evaluate their consistency with respect to best track and SFMR airborne measurements. Specifically, the potential of SAR high-resolution observations for estimating Rmax is discussed. 161 SAR acquisitions have thus been collected resulting in the first extensive SAR-TC database. They sample all TC intensity categories occurring in five different TC basins, and include 29 collocations with SFMR. After precisely locating TC center and areas contaminated by heavy precipitations, Vmax, Rmax, and outer wind radii (R34/50/64 kt) are extracted from each acquisition. The data and methodology used are in section 2. TC structure parameters are then compared with best track from JTWC and NHC and SFMR estimates in section 3. Section 4, provides insights and in-depth analysis about limitations, e.g., rain impacts on C-band SAR measurements. Finally, section 5 summarizes the main outcomes of the present analysis, and provides prospects for future investigations.

\section{Data and method for SAR analysis}

\section{a. Synthetic aperture radar}

This study benefits from three different C-band synthetic aperture radar (SAR) missions including Sentinel-1A $(S 1 A)$, Sentinel-1B $(S 1 B)$, and RadarSat-2. $S 1 A$ and $S 1 B$ are polarorbiting satellites operated by Copernicus/European Space Agency and were launched in 2014 and 2016, respectively. RadarSat-2 is a polar-orbiting satellite operated by the Canadian Space Agency (CSA) and was launched in 2007. All current SAR missions have several exclusive acquisition modes and cannot continuously acquire data, but rather acquisitions are scheduled. A dedicated acquisition strategy is thus mandatory to maximize tropical cyclone (TC) observations. The hurricane watch program (Banal et al. 2007) for RadarSat, and more recently, the Satellite Hurricane Observation Campaign (SHOC) (Mouche et al. 2019) for Sentinel-1 and RadarSat-2 were dedicated efforts that have maximized the collection of SAR measurements over TCs.

$S 1 A, S 1 B$, and RadarSat-2 can be operated in wide swath modes and can acquire C-band backscatter measurements with different polarization states. Polarized radar images of the same scene can thus be combined for geophysical parameters retrieval. For ocean surface wind measurements over TCs, one generally uses the polarization configuration $\mathrm{VV}+\mathrm{VH}$, the antenna emitting electromagnetic waves in $\mathrm{V}$ polarization and receiving in both $\mathrm{V}$ and $\mathrm{H}$ polarization states. Here, the database solely builds on SAR observations in this polarization configuration acquired in wide swath modes. The swath widths range from 250 to $500 \mathrm{~km}$ depending on the sensor and/or modes. In comparison to other polar orbiting sensors such as radiometers or scatterometers, SAR swaths are smaller. However, SAR product resolution is much higher than other active or passive polar orbiting systems. Native product (i.e., Level 1 product from the Space Agency before applying the wind retrieval algorithm) resolutions used here to estimate the ocean surface wind speed are 20,50 or $100 \mathrm{~m}$ depending on sensor and/or modes. 
The ocean surface wind retrieval algorithm follows the initial approach proposed by Mouche et al. (2017) and further refined for major hurricanes (Mouche et al. 2019). The method relies on the joint use of both co- and cross-polarized signals, befitting from both the copolarized signal's sensitivity and high signal-to-noise ratio for low to moderate wind speeds (i.e., below $25 \mathrm{~m} \mathrm{~s}^{-1}$ ), and from the cross-polarized signal sensitivity to very high wind speeds (Zhang and Perrie 2012). Compared to actual scatterometer measurements, the use of crosspolarized signals is key to mitigate the wind speed sensitivity issues often reported for copolarization backscatter signals (Quilfen et al. 1998).

A representative example of this co- and cross-polarization capability was provided in Mouche et al. (2019) where $S 1 A / B$ measurements led to wind speed estimates ranging from 10 to $75 \mathrm{~m} \mathrm{~s}^{-1}$ in Hurricane Irma (2017) on 7 September when the storm was estimated to have category-5 intensities. Irma's wind speed estimates were compared to collocated SFMR estimates and the overall bias, root mean squared error (RMSE), and correlation were $1.5 \mathrm{~m} \mathrm{~s}^{-1}, 5.0 \mathrm{~m} \mathrm{~s}^{-1}$ and more than $90 \%$, respectively. It is, however, important to note that the C-band backscatter measurements can have contributions from ocean surface winds and rainfall (Katsaros et al. 2000; Li et al. 2013), possibly leading to significant localized contamination in the wind speed estimates. In Hurricane Irma, the respective contribution of both wind and rain in areas with rain rates exceeding $45 \mathrm{~mm} \mathrm{~h}^{-1}$ and close to the TC center (30-35 km) was unclear. Rainfall was found to lead to about a $10 \%$ uncertainty in wind estimates (Mouche et al. 2019). Local gradient analysis of the radar backscattered signals (Koch 2004) is systematically performed in the present analysis to help identify localized regions where both rain and wind contribute to the C-band signals.

Figure 1 shows an example of SAR wind speeds acquired in Hurricane Irma on 8 September and Fig. 2a shows the coincident cross-polarization backscatter. The retrieval resolution, in this case, is $3 \mathrm{~km}$ and the backscattered signals range from -35 to $-17 \mathrm{~dB}$. The backscatter has a clear minimum within the hurricane's eye. Backscatter then increases outward this minimum area with rapid signal increases, corresponding to the radius of maximum winds. Specific features related to rain events can be traced in the backscatter signal. In the northwestern part, a bright pattern with a semicircular shape is detected and corresponds to an area of significant rainfall. Mouche et al. (2019) showed that rain impacts can also be associated with a small darker circular ring encircling an area just outside the largest backscatter signals and winds near the eye region (noticeable in section 4 b example). Such a sudden signal decrease corresponds to very localized and heavy precipitationfitting the general eyewall structure found in Hurricane Allen (1980) discussed in Jorgensen (1984). SAR thus provides instantaneous measurements of radar backscatter signals from very localized ocean surface areas. Here, a 3-km-resolution grid is adopted, which corresponds to the area that would be affected by a 1 min sustained $50 \mathrm{~m} \mathrm{~s}^{-1}$ wind speed.

\section{b. Best track and SFMR}

TC best tracks that are prepared by different Regional Specialized Meteorological Center (RSMCs) and Tropical

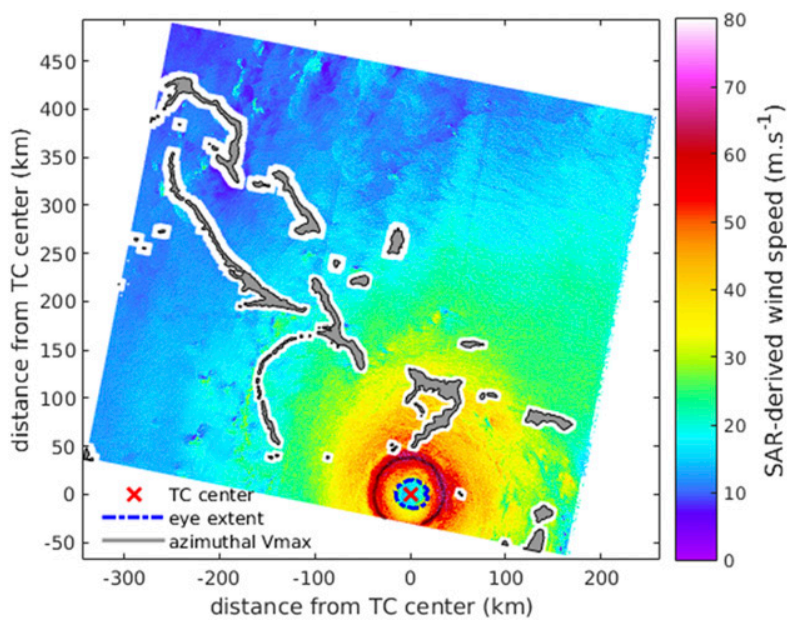

FIG. 1. Illustration of our methodology approach with the example of the SAR-derived wind field of category-5 Irma on 8 Sep 2017. The grid displayed is a Cartesian projection of $1 \mathrm{~km}$ and $0.5^{\circ}$-resolution polar grid, with TC eye center as origin. Dashed blue and black solid contours delineate, respectively, the eye extent and the azimuthal Vmax ring.

Cyclone Warning Center (TCWCs) depending on their areas of responsibility, provide 6-hourly estimates of location, intensity and other parameters covering each TC's life cycle. Initiated from near-real-time observations, these analyses are revisited after the TC seasons to take benefit of all available measurements, from surface information such as buoys, weather radars, platforms, up to aircraft, dropsondes and satellite remote sensors (Knapp et al. 2010), and are a subjectively smoothed representation of a tropical cyclone's history (Landsea and Franklin 2013). The analyses are performed by each RSMC, according to the data availability, not the same for each area, e.g., geostationary observations, their own strategy and conventions, e.g., time averaging periods. The gathering of all these information into a global and homogeneous database is thus not straightforward (Kruk et al. 2010), and is part of the efforts carried out to build the IBTrACS database (Knapp et al. 2010). A TC analysis starts by determining the TC location and the maximum sustained wind speed (Vmax), before including other parameters, such as wind radii or radius of maximum wind speed (Rmax), to refine the wind structure characterization. Specifically, three different wind radii are defined for each of the four geographical quadrant (NE, SE, SW and NW). These parameters provide the estimates of the maximum extent with wind speed greater than 34 (R34), 50 (R50), and 64 (R64) knots. Note, all RSMCs and TCWCs do not distribute these parameters.

In the following, we only focus on analyses from the NHC and the JTWC centers. At present, NHC and the JTWC both reanalyze R34, R50, and R64 following the season, but do not reanalyze Rmax (Knaff et al. 2016). Indeed, both centers rely on the Automated Tropical Cyclone Forecasting (ATCF) system, designed to ease and harmonize forecast processing and track record (Miller et al. 1990; Sampson and Schrader 2000), with estimates of Rmax and wind radii, and the same convention for time averaging. In addition, both centers create 
IRMA Tropical Cyclone

SAR from 2017/09/08 10:53 to 2017/09/08 10:55 UTC SFMR from 2017/09/08 08:53 to 2017/09/08 12:53 UTC

(a)

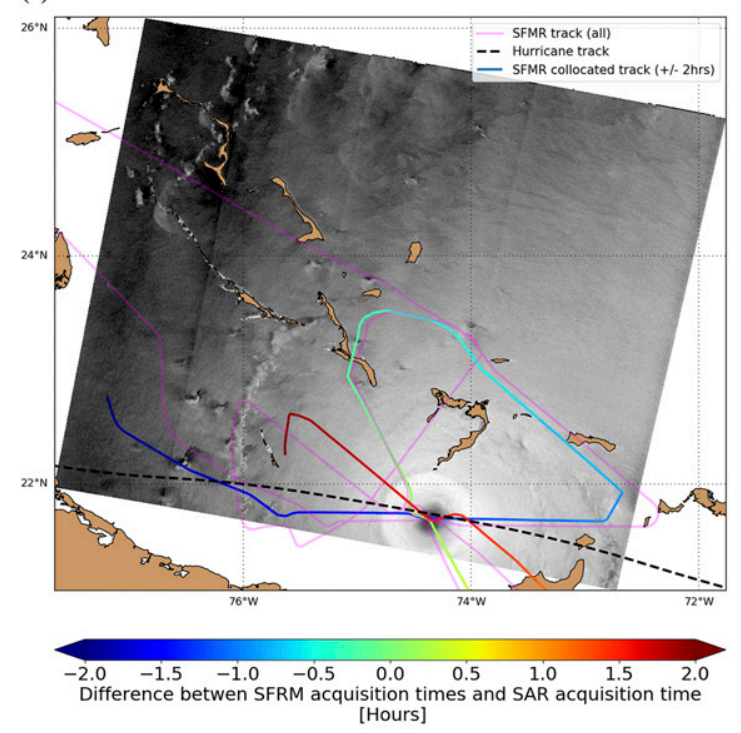

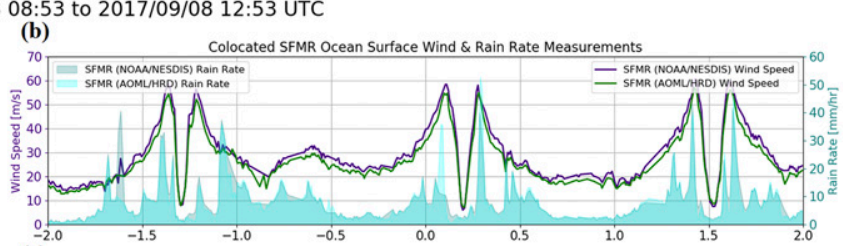

$$
\text { (c) }
$$
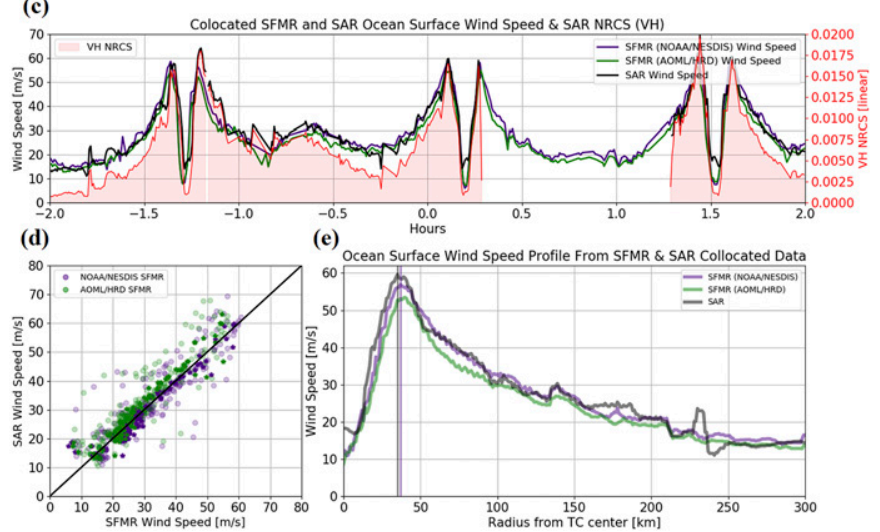

FIG. 2. Example of collocation and coanalysis between SAR and SFMR measurements in the case of Irma on 8 Sep 2017 (a) SAR backscattered signal in cross-polarization from RadarSat-2 SAR from 1053 to 1055 UTC. (solid pink line) SFMR measurements location during hurricane hunters flight from 0853 to 1253 UTC. (colored line) Collocated SFMR measurements location within a time window of $\pm 2 \mathrm{~h}$ centered on SAR acquisition start time. Changes in color indicate the time difference between SAR and SFMR measurements. (b) Collocated SFMR ocean surface wind speed (purple and green) and rain rate (blue and cyan) measurements with respect to time difference between SAR and SFMR measurements. (c) Ocean surface wind speed measurements from SAR (black) and SFMR (purple and green) and SAR backscattered signal (red) in cross-polarization evolution with respect to time difference between the two sensors. (d) Direct comparison between SAR and SFMR wind speed (green and purple). (e) Ocean surface wind speed profile with respect to distance from TC center as measured from collocated SFMR (green and purple) and SAR (black) measurements within a $\pm 2 \mathrm{~h}$ time window. Vertical bars indicate the maximum of wind as given by the two sensors.

best track analyses for all storms, offering a homogeneous dataset for comparisons with SAR derived parameters over all five different ocean basins. In absence of IBTrACS data, ATCF archive (only 2018 cases) is solely used. Overall, the different strategies and methods to estimate TC parameters remain similar. Vmax is mainly inferred by the Dvorak analysis in combination to cloud pattern recognition from visible and infrared (IR) satellites to TC intensity (Velden et al. 2006, 2017), but at times can also consider other methods and aircraft reconnaissance, when available. $\mathrm{R} 34, \mathrm{R} 50$, and $\mathrm{R} 64$ wind radii are derived from scatterometers, cloud/feature-tracked winds, new L-band passive radiometer measurements (Reul et al. 2016; Meissner et al. 2017) and other operational techniques (Knaff et al. 2011, 2015), including IR (Kossin et al. 2007) or microwave sounder (Demuth et al. 2004, 2006). At last and despite its aforementioned importance, Rmax is generally subjectively estimated, except when airborne data from SFMR or flight level are available.

If other methods exist (Lajoie and Walsh 2008), they are all indirect methods as they do not retrieve any ocean surface wind field before providing the wind radii estimates. To note, neither JTWC nor NHC have been using SAR data for their analyses. Therefore, in addition of being the most integrated and quality-controlled data source, best track analysis is an independent source of comparison.
Rain rates and ocean surface wind speeds from the SFMR are also used as independent measurements. Since its first experimental flight in 1980 through Hurricane Allen, SFMR is now installed on all U.S. hurricane reconnaissance aircraft to routinely and operationally provide wind and rain estimates during TC events. The concept relies on the use of a C-band radiometer operating at six different frequencies ranging from 4.5 to $7.2 \mathrm{GHz}$ with different sensitivities to foam coverage at the sea surface (related to ocean surface wind speed) and to rain (Uhlhorn and Black 2003).

Over the course of time, retrieval algorithms have been further improved, as the possibilities to refine the filtering of the data and better describe the brightness temperature dependency to wind and rain increase with the number of available flights (Uhlhorn et al. 2007; Klotz and Uhlhorn 2014). Recently, Sapp et al. (2019) proposed new improvements including a bias correction to calibrate the whole dataset, a new model for flat-surface emissivity (Meissner and Wentz 2012), a new frequency dependence for the atmospheric transmissivities, leading to a new method and formulation to derive the relationship between the wind excess emissivity and the ocean surface wind speed (so-called wind GMF, for Geophysical Model Function). In particular, arguing on possible nongeophysical contamination of the lower-frequency channel, the highest-frequency channel has been considered to derive a new 
wind GMF (and its frequency dependency). This also imposed modification of the rain absorption model coefficient to maintain the initial rain rates performances (Klotz and Uhlhorn 2014). Overall, SFMR wind speeds are expected to be higher than operational products for wind speeds larger than $15 \mathrm{~m} \mathrm{~s}^{-1}$ and are judged as nonreliable for rain rates measurements larger than $45 \mathrm{~mm} \mathrm{~h}^{-1}$ (Sapp et al. 2019). This study does not aim to discuss the two existing SFMR products, and mainly relies on products processed and provided by NOAA/NESDIS (Sapp et al. 2019). For sake of completeness, results obtained with AOML/HRD products are also considered in the methodology section (see section 2c), and in the discussion section (see section 4).

Because the SFMR design involves a single nadir-viewing antenna, only transects are available. Despite these limitations, the combined estimates of rain rate and ocean surface wind speed at very high resolution (temporal resolution is $1 \mathrm{~s}$ ) makes this instrument unique for validating SAR-derived wind speeds and to discuss the possible rain impacts, especially in the TC inner core.

\section{c. Methodology}

While the subjectively smoothed best track content already results from a multisource reanalysis, SFMR and SAR provide more localized measurements. Although SAR and SFMR can both be used to derive local ocean surface wind speeds, their differences in coverage and temporal resolution need to be considered in order to build meaningful comparisons. A specific methodology to coanalyze SAR measurements with each of these sources is needed.

To prepare for the evaluation of SAR's ability to estimate Vmax, Rmax, and wind radii parameters, a three-step approach is proposed to extract those same parameters from the SAR wind products: 1) find the TC center, 2) identify the azimuthal Vmax ring and Rmax, 3) compute mean wind radii values. Irma's SAR-derived wind field on Fig. 1 illustrates the different processing steps:

- TC center: The TC position is first linearly interpolated using the best track at satellite-acquisition time. In the vicinity of this position $(100 \mathrm{~km})$, the signal contrast is computed for the two polarized images. Selecting the one with the strongest gradient, we search for the location of the signal intensity minimum. These locations are then averaged to get a second TC center guess, used to remap the SAR wind on a polar grid. The retained polarization channel and the wind speed map are further jointly coanalyzed with the heterogeneity mask to estimate the maximum gradient in all azimuth directions and to derive the eye extent (see dashed blue line on Fig. 1), from which the mean center is computed to obtain the TC center (see red cross on Fig. 1). A new polar grid centered on this TC center is then defined, resolution $1 \mathrm{~km}$ in distance and $0.5^{\circ}$ in direction.

- Vmax and Rmax: The first Rmax estimate is defined as the closest peak to the TC center obtained from the azimuthally averaged 1D radial wind speed profile. Based on this first guess, we further derive Rmax for each available azimuth angle of the polar grid (black line on Fig. 1). SAR-derived
Vmax is defined as the 99th percentile of the wind speed values associated to the azimuthal $\mathrm{Rmax}$ values. SARderived Rmax is then simply the radius corresponding to this percentile.

- Wind radii: The 34-, 50- and 64-kt wind radii are estimated for the four geographical (NE, NW, SW, SE) quadrants. For each quadrant we search for the closest radial values above the wind speed threshold $(34,50$, or $64 \mathrm{kt})$ in all of the quadrant's azimuth directions. We then keep the $10 \%$ of the largest values associated to the corresponding wind speed, to provide a SAR-derived wind radii. Estimates are considered optimal when quadrants are at least $50 \%$ complete. Under this threshold, they are not calculated. The use of the 90th percentile for deriving the maximum extent of the wind radii from high-resolution satellite wind measurements allows to filter unrealistic outliers.

Finally, for SAR-BTK comparisons, we linearly interpolate best track at satellite acquisition time for each TC parameters as instantaneous SAR measurements rarely match synoptic times.

Here we examine SAR's capabilities for measuring ocean surface wind speed near the inner core of TCs, including Vmax and Rmax, by using nearly coincident SFMR wind speed measurements. The two main differences between SAR and SFMR observations are (i) the duration required to sample a given TC and (ii) the coverage of the TC structure. For the Irma TC case presented in Fig. 2, SAR data are acquired in less than 3 min, while the SFMR data collection lasts more than $9 \mathrm{~h}$. While the "multi-alpha" reconnaissance pattern (the solid purple line) is designed to sample the $2 \mathrm{D}$ aspects of the TC, it can only do so in a low-spatial-resolution and temporally averaged manner. A two-step procedure has been adopted (see Mouche et al. 2019 for details) to best compare SFMR and SAR wind speeds. SFMR measurements are resampled at $3 \mathrm{~km}$ resolution, and the time differences are taken into account between each SFMR measurement and the SAR acquisition time following storm motion. As shown in Fig. 2a, this procedure shifts the initial SFMR measurements locations (purple solid line) with respect to SAR acquisition time into a collocated track (colored solid line). In addition, to further mitigate the time difference impact, only collocations within $\pm 2 \mathrm{~h}$ are considered. Figure $2 \mathrm{~b}$ illustrates SFMR wind and rain measurements along the transect used for colocating in the Hurricane Irma, while Fig. 2c shows the corresponding radar backscattered signal in cross-polarization (red) and the wind speed measured by the SAR (black). As expected from previous studies (Zhang and Perrie 2012; Mouche et al. 2019), the correlation between radar signal and SFMR wind speed is very high, and the two sensors are able to capture the TC characteristics within the inner core. Finally, wind speeds from SAR and SFMR can be directly compared (see Fig. 2c). In particular, when the collocation time is less than $30 \mathrm{~min}$ and during the transect across the hurricane eye, we note the remarkable agreement for wind speeds ranging from 15 to $60 \mathrm{~m} \mathrm{~s}^{-1}$. This example also illustrates the difference between wind speed measurements obtained when using NOAA/NESDIS or AOML/HRD products. Although the shape of the two wind 

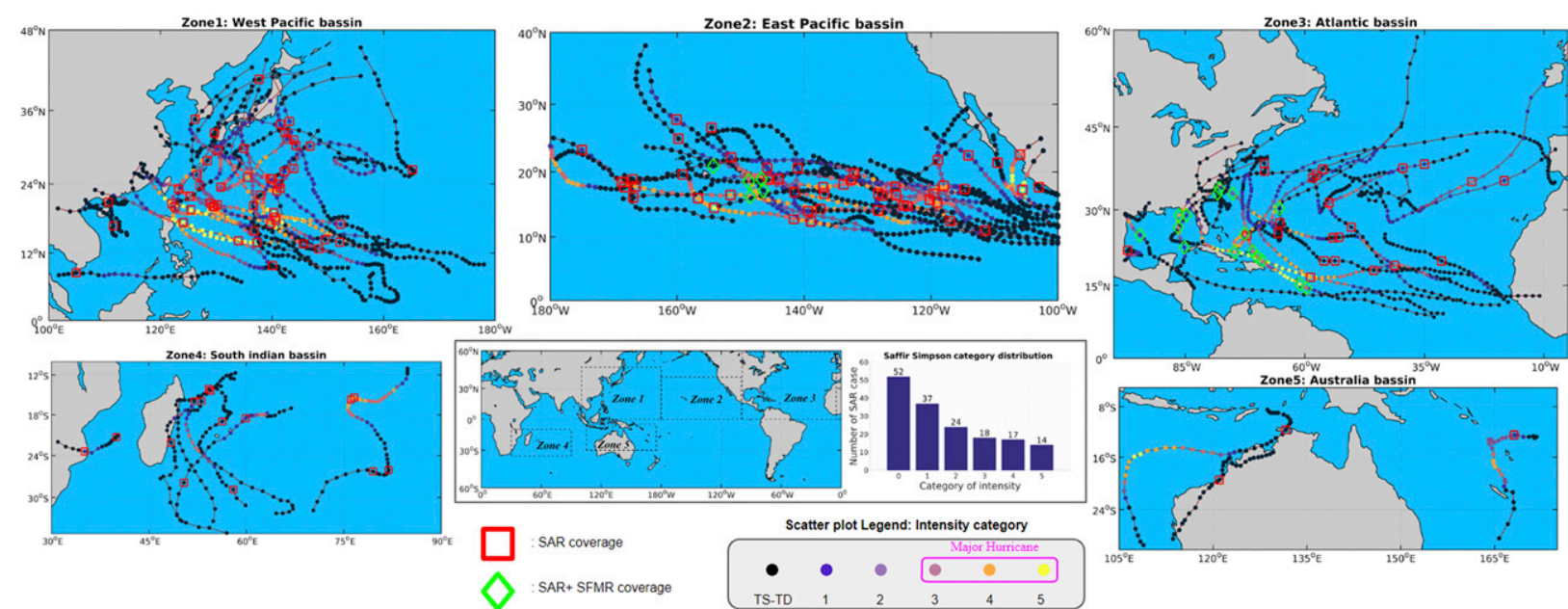

FIG. 3. Composite view of TC cases data constellation for each geographical zone; basin locations are indicated in the global map. Lifetime positions from best track are displayed for each TC; colors depict intensities with respect to Saffir-Simpson scale. Markers are stated for TC positions with measurements. Red squares indicate SAR measurements only and green diamonds indicate sequential measurements of SAR and SFMR.

speed transects from SFMR remain very similar, we can notice differences for the highest values of wind speeds. The impact on SAR comparison is further illustrated on Fig. 2d. However, SFMR measurements may not necessarily cross the area corresponding to the maximum wind speed. Consequently, Rmax parameter cannot always be derived from SFMR measurements. To overcome this limitation, we introduce the "effective Rmax" parameter. It is defined as the radius of maximum wind speed obtained from all the SFMR transects collocated with SAR measurements. These transects are combined to derive a single averaged wind speed profile for each of the two sensors from which the maximum of wind speed and corresponding radius can be estimated. This is illustrated on Fig. 2e. The averaged wind profile derived from SFMR collocated transects is shown (solid purple line) with respect to the distance from TC center. Here the maximum wind speed and the corresponding effective Rmax are about $60 \mathrm{~m} \mathrm{~s}^{-1}$ and $37 \mathrm{~km}$, respectively (see solid vertical purple bar). When applying the same method to the SAR collocated wind measurements, we obtain a very similar wind profile (see solid gray line), yielding an effective Rmax of $35 \mathrm{~km}$ that can be directly compared to SFMR estimate. Figure 2e also presents the two different wind speed profiles obtained with the two SFMR products available. As anticipated with the transect illustration, these products yield to some differences for the highest wind speed values, but not for the effective Rmax. This analysis has been applied to all available collocated SAR/SFMR data (see section 3).

\section{d. Dataset overview}

Thanks to the SHOC campaign, a total of 194 acquisitions have been obtained, enabling an unprecedented SAR TCs collection over all five distinct TC basins. So far, only the North Indian Ocean is missing, but acquisitions have been pursued in 2019. Best track analysis is available for all cases, with a total of
29 collocated SFMR flights. Yet, as discussed in section 2c, specific requirements such as the mandatory presence of a complete eye structure are imposed. Two situations prevent our analysis procedure: 1 ) when the swath border intersects the Rmax and 2) when land contaminates the retrievals ( $>75 \%$ of the full scene). Both situations effectively prevent a full eye or eyewall description. In addition, cases without clear eye structures ( $\sim$ seven cases discussed in section 4$)$ were removed. Overall, about $85 \%$ of initial acquisitions are preserved.

After this quality control step, 161 snapshots corresponding to 72 different tropical systems in the period 2015-18 can then be analyzed. Figure 3 synthesizes the dataset. For each storm, the 6-h best track locations with corresponding storm intensity (colors) is indicated. Specific markers highlight the collocation opportunities: A red square when only-SAR is available and a green diamond when simultaneous $\mathrm{SAR}+\mathrm{SFMR}$ measurements coexist. Because aircraft measurements are restricted to North Atlantic and eastern North Pacific basins, with a majority occurring in the Atlantic, collocations with SFMR amount to only $13 \%$ of the dataset, with a total of 23 Atlantic and 6 Pacific flights. $70 \%$ of Atlantic hurricanes cases are actually retained. The intensity histogram shown in the bottom panel of Fig. 3 illustrates the spectrum of TC intensities. Unlike most of previous SAR-based studies, all Saffir-Simpson categories are sampled. Therefore, this dataset captures the general distribution and basins properties observed in climatology studies (Chan and Chan 2012; Knaff et al. 2014; Chavas et al. 2016), in terms of size and activity.

To complement this SAR dataset, we also collocate rainfall information from two different sources: the half-hourly Integrated Multisatellite Retrievals for GPM (IMERG) product, with $0.1^{\circ}$ resolution and global coverage (Huffman et al. 2019), and specific NOAA Next Generation Weather Radar (NEXRAD) network samples, with an $1 \mathrm{~km}$ range and $1^{\circ}$-azimuth high resolution for a $450 \mathrm{~km}$ coverage. IMERG is systematically used to identify cases 
(a)

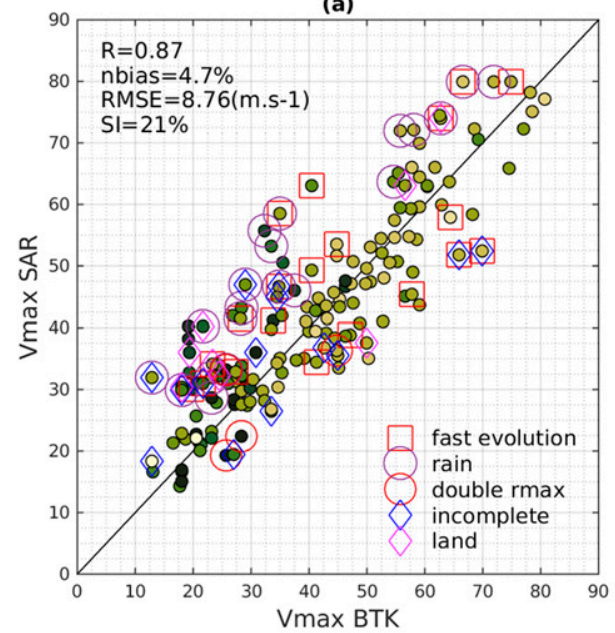

(b)

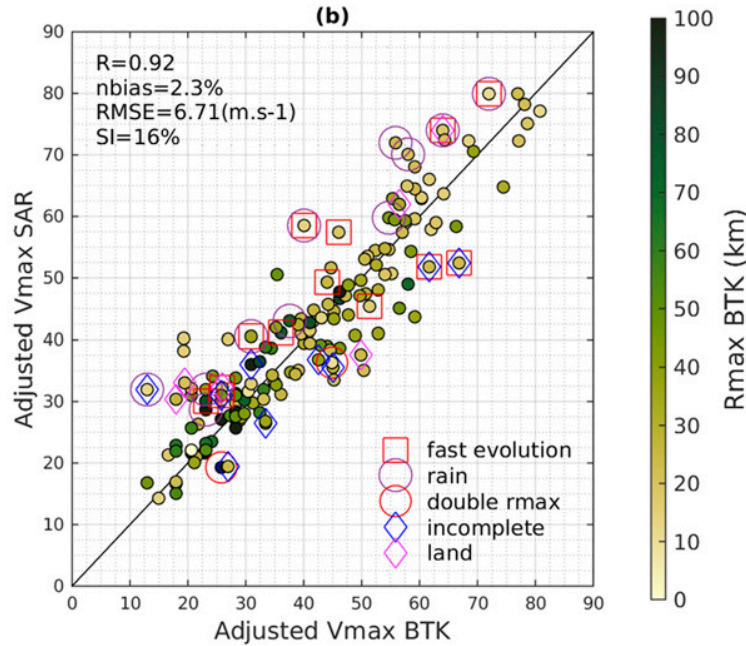

FIG. 4. Comparison of best track and SAR-derived Vmax. Disturbance sources are indicated with specific markers to guide analysis. Correlation $(R)$, normalized bias (nbias) calculated as $\left(\operatorname{Vmax}_{\mathrm{SAR}}-\mathrm{Vmax}_{\mathrm{BTK}}\right) / \mathrm{Vmax}_{\mathrm{BTK}}$, root-mean-square error (RMSE), and scattering index (SI) are added as statistical tools. Comparison (a) before and (b) after treatments of flagged values.

with heavy rain situations $\left(>35 \mathrm{~mm} \mathrm{~h}^{-1}\right)$, around the inner-core region. Regarding NEXRAD, specific cases have been selected to help discussing precipitation impacts on C-band sensors (Katsaros et al. 2000; Mouche et al. 2019).

\section{Comparison of TC parameters}

\section{a. Ocean surface wind speed}

We follow the three-step approach detailed in section $2 \mathrm{c}$ for the 161 quality-controlled SAR cases. Results obtained for Vmax, are shown in left panel of Fig. 4. Overall, there is a strong correlation $(R=0.87)$ and low bias $(4.7 \%)$ between best track and SAR Vmax estimates. A larger scatter is noticeable, mainly in the vicinity of $10-40 \mathrm{~m} \mathrm{~s}^{-1}$. It leads to a RMSE around $9 \mathrm{~m} \mathrm{~s}^{-1}$. We further define specific flags to isolate potential contamination sources in these comparisons, possibly resulting from uncompleted TC wind field due to land (pink diamond) or swath issues (blue diamond), TC with double eye Rmax (red circle) and rain signature (purple circle). It is also possible that Vmax comparisons are biased by the 6-hourly and smoothed nature of best track analysis, especially for cases with rapidly evolving intensities [red squares for $|d v / d t|>10 \mathrm{kt}$ $\left.(6 \mathrm{~h})^{-1}\right]$. Specific data processing methods are thus considered, corresponding to three possible situations: 1) Fast evolving cases: as a TC intensity may not vary linearly, we simply choose the closest time instead of the interpolated one; 2) heavy rain $\left(>30 \mathrm{~mm} \mathrm{~h}^{-1}\right)$ : in presence of ambiguous peak, we select the second maximum wind speed in area where IMERG rain rate is lower than $30 \mathrm{~mm} \mathrm{~h}^{-1}$;3) double Rmax: in case of an eyewall replacement cycle (ERC), we select the SAR Vmax associated with the closest ring to the best track Rmax estimate. These corrections define what we called the "adjusted"'SAR or best track Vmax, to yield new comparisons presented in the right panel of Fig. 4. Statistics slightly improve, with higher correlation $(R=0.92)$ and lower normalized bias
$(2.3 \%)$. Some of the scatter is also related to uncertainties in the best track intensity estimates (Torn and Snyder 2012; Landsea and Franklin 2013).

The methodology discussed in section $2 \mathrm{c}$, is applied to the collocated SFMR/SAR dataset presented in section $2 \mathrm{~d}$. Results and summary statistics are presented in Fig. 5. Overall (blue and red dots together), a high correlation $(R>0.90)$, small bias $\left(<0.5 \mathrm{~m} \mathrm{~s}^{-1}\right)$ and RMSE $\left(<5 \mathrm{~m} \mathrm{~s}^{-1}\right)$ are obtained. An additional filtering to solely select collocated measurements obtained within \pm 30 min can be applied (red dots). This improves the statistics-particularly for RMSE now at about $4 \mathrm{~m} \mathrm{~s}^{-1}$. As discussed by Mouche et al. (2019), most outliers are associated with subtle errors in collocating points, which can adversely affect verification statistics performed at such high resolution. This sensitivity is particularly large in the eyewall region where a few kilometers of error in the collocation can lead to significant differences in wind speeds in a steady intensity state. To note, these results are obtained when SFMR measurements are considered as valid, i.e., excluding measurements with rain rates larger than $45 \mathrm{~mm} \mathrm{~h}^{-1}$ (Sapp et al. 2019). Using only the 29 SFMR cases clearly shows that SAR provides high quality ocean surface wind speed measurements up to $70-75 \mathrm{~m} \mathrm{~s}^{-1}$.

\section{b. Wind structure}

Here we compare best track estimates of Rmax and wind radii to those calculated from SAR (see section 2c). Figure 6 presents all values obtained for the three wind radii (R34: green; R50: blue; R64: yellow), and includes all geographical quadrants. Correlation is high, larger than 0.85 for the three wind radii. The normalized bias is negligible (about $-3 \%$ ) for R34 and R50, but about 10\% for R64. R64 from SAR are generally larger than values given in the best track. The scatter index increases with wind speed values associated to the radii, yielding to $29 \%$ for R64. As mentioned, best track parameters 


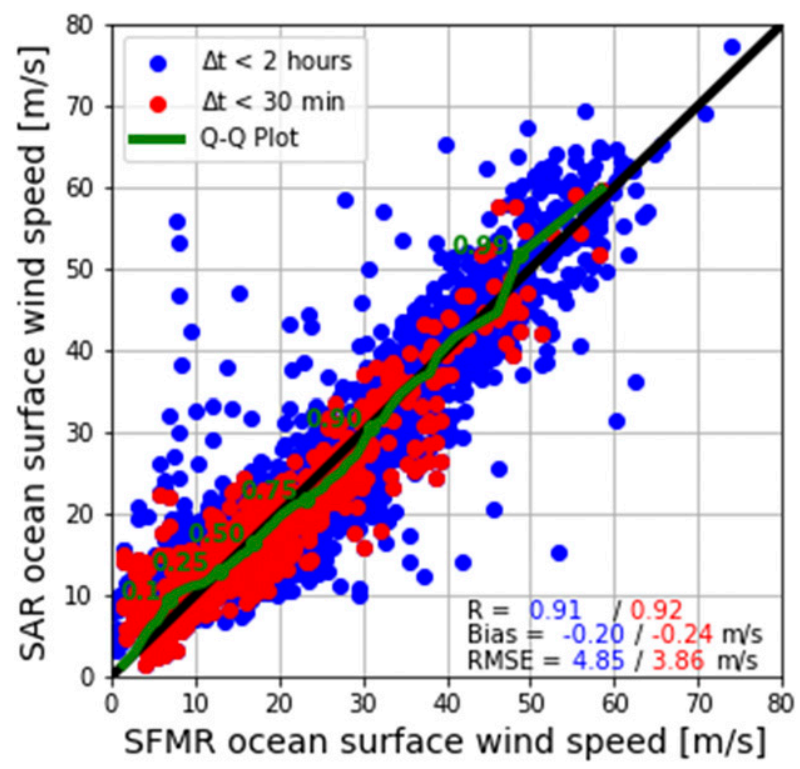

FIG. 5. SFMR-derived ocean surface wind speed vs SAR-derived ocean surface wind speed. Resolution is $3 \mathrm{~km}$. Blue dots indicate the collocated data within $\pm 2 \mathrm{~h}$ and red dots within $\pm 30 \mathrm{~min}$. Green line is the quantile-quantile $(\mathrm{Q}-\mathrm{Q})$ plot applied to collocated data within $\pm 30 \mathrm{~min}$, some of the main quantiles are indicated for convenience (green).

are mostly derived from indirect methods (section $2 \mathrm{~b}$ ) or loworbit satellite missions using medium to low-resolution (12.5$50 \mathrm{~km}$ ) observations (Brennan et al. 2009; Meissner et al. 2017). This could explain the observed spread, especially, the increasing scatter index for R64 that typically has values less than $100 \mathrm{~km}$. In addition, radii associated to higher winds may have higher temporal variability (Chavas and Lin 2016), possibly not captured by the 6-hourly best track analysis-especially if the estimate relies on sparse low-orbit satellite measurements. The number of wind radii available in the best track $\left(N_{\text {total }}\right.$ in legend of Fig. 6$)$, from SAR data $\left(N_{\mathrm{SAR}}\right.$ in the legend of Fig. 6$)$, and that are used for the comparison $\left(N_{\text {coloc }}\right.$ in legend of Fig. 6$)$ are also indicated for each wind radii on Fig. 6. Due to swath issues (e.g., the southern part in Fig. 1) preventing a complete TC structure description, SAR measurements are sometimes unable to estimate wind radii in all geographical quadrants and/or at all wind thresholds. Consequently, for R34 generally associated with the largest radius, only about $50 \%$ of the best track values can be compared, whereas this number rises to about $70 \%$ and $90 \%$ for R50 and R64, respectively. Note that the existence of the best track wind radii is dictated by the best track intensity (for instance R50 and R64 do not exist for tropical storms with $\operatorname{Vmax}<50 \mathrm{kt}$ ). So the best track does not always have wind radii values to compare to SAR. This explains the difference between $N_{\mathrm{SAR}}$ and $N_{\text {coloc }}$ parameters. In particular, $N_{\mathrm{SAR}}=354$ and $N_{\text {coloc }}=$ 286 parameters for R64 indicates that SAR observations provide more R64 estimates than best track. This difference decreases for R50 and R34, suggesting resolution issues in R64 estimates.

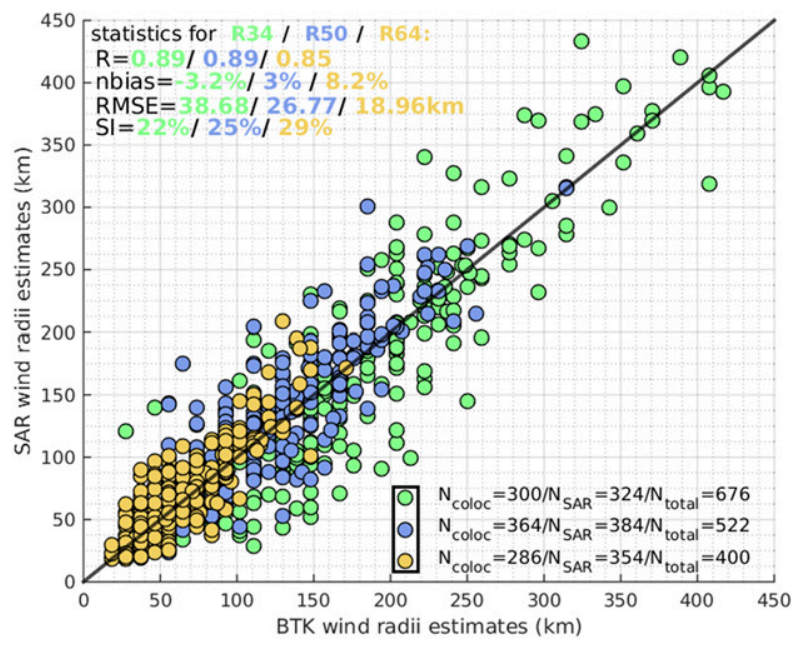

FIG. 6. Comparison of best track and SAR-derived maximum extent quadrant wind radii. Extents from SAR are inferred from the mean quadrant of the $10 \%$ largest values. All quadrants' wind radii estimates are included; colors of both statistics and chart are set accordingly: green indicates R34, blue indicates R50, and yellow indicates R64. Statistical tools used are as in Fig. 4.

Results of comparisons of Rmax are shown in Fig. 7a. As for Vmax, additional corrections can be applied (see Fig. 7b) to account for best track or SAR parameter uncertainties. Contrary to Vmax, large scatter index $(\sim 50 \%)$ and RMSE $(\sim 25 \mathrm{~km})$ are found and persist despite additional corrections. The bias remains almost constant. Correlation increases (from 0.47 to 0.73 ), but it is mostly governed by double eyewall cases, which strongly impact the estimates. Below category-1 TC, tropical depressions and storms rarely exhibit a complete eye (Vigh et al. 2012). When discarding these cases, for which Rmax and TC center definition can be quite subjective, a clear improvement is obtained, with a reduced RMSE $(11.6 \mathrm{~km})$ and scatter index (32\%). Yet, the spread is still high and bias remains unchanged (SAR-derived Rmax are globally smaller). A binning of the Rmax values from best track is also noticeable in the vicinity of $20-40 \mathrm{~km}$. Overall, this comparison reveals an overestimation of Rmax parameters from the best track when compared to SAR estimates, for all TC intensities available in our study.

To compare the effective Rmax from SAR and SFMR, as defined in section $2 c$, we only examine hurricane strength cases in the SAR-SFMR collocated dataset. Seventeen cases of the 29 available are ultimately used. Figure 8 a presents comparisons and associated statistics of effective Rmax. The color code indicates SFMR maximum wind speed for each case. Again, the agreement is very good with correlation coefficient larger than 0.70, RMSE of $12 \mathrm{~km}$ and bias lower than $5 \mathrm{~km}$. SAR measurements provide Rmax values from 10 to $70 \mathrm{~km}$, with no significant dependency with respect to current intensity. The present analysis, however, yields two clear outliers, i.e., the two dots within the purple ellipse on Fig. 8a. They are both corresponding to data acquired over Hurricane Florence around 1100 UTC (SAR acquisition 
(a)

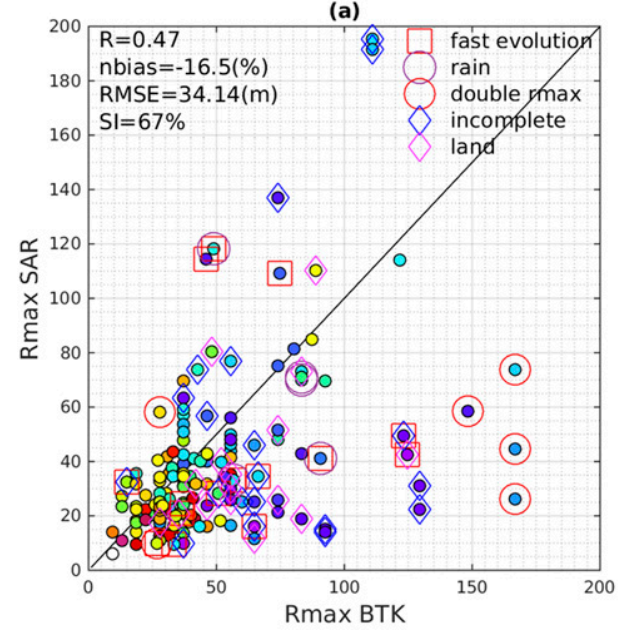

(b)

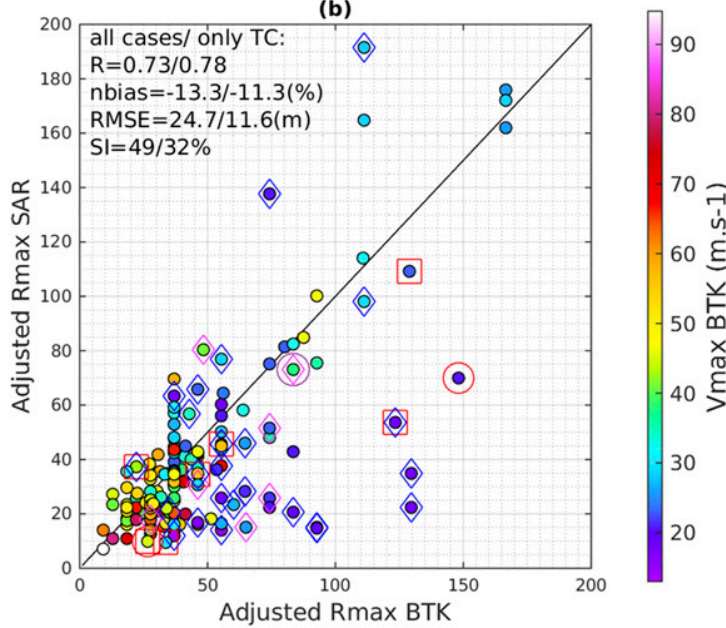

FIG. 7. Comparison of best track and SAR-derived Rmax. Markers and statistical tools are similar to the Fig. 4 convention. Comparison (a) before and (b) after treatments of flagged values. Statistics for solely cases $>33 \mathrm{~m} \mathrm{~s}^{-1}$ are also included.

time), 13 and 14 September 2018. Figures $8 \mathrm{~b}$ and $8 \mathrm{c}$ shows SAR-SFMR collocated measurements and the corresponding SAR- and SFMR-derived wind profiles for the first outlier. Collocated transects exhibit a significant difference in the wind speed variation close to the eyewall (see within red circle in Fig. 8b), where SFMR measured a rain rate larger than $30 \mathrm{~mm} \mathrm{~h}^{-1}$ and wind speed of $40 \mathrm{~m} \mathrm{~s}^{-1}$. This inconsistency between SAR and SFMR leads to a slightly different shape for the wind speed profile, as displayed Fig. 8c, and finally to a difference in the effective Rmax estimate. When the two outliers are filtered out, correlation coefficient increases, to become larger than 0.95, whereas RMSE and bias decrease to about $3.5 \mathrm{~km}$ and $500 \mathrm{~m}$, respectively. Although a simple filtering of local maxima with respect to the TC center distance would have removed these outliers, we considered them to further illustrate possible rain impact on C-band derived wind speed.

\section{c. Best track error estimates}

Assuming SAR-derived parameters as reference values, we further analyze TC inner (Vmax and Rmax) and outer (wind radii) core parameters as given by best track with respect to storm category. Figure 9 displays the mean values from SAR and best track for each of these TC parameters as a function of storm category. The related uncertainty (top panels) and mean absolute error (MAE) (bottom panels) are indicated for both inner (left panels) and outer core parameters (right panels).

Most SAR- and best track-derived TC parameters (i.e., Vmax and wind radii) have similar trends in mean values and MAE with respect to intensity (with exception of TS/TD). (a)

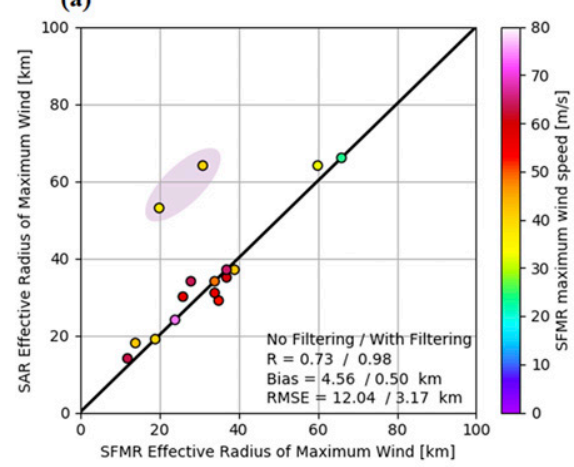

(b)

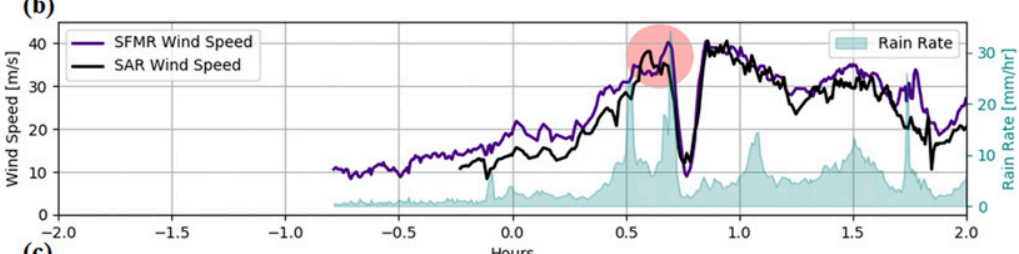

$$
\text { (c) }
$$

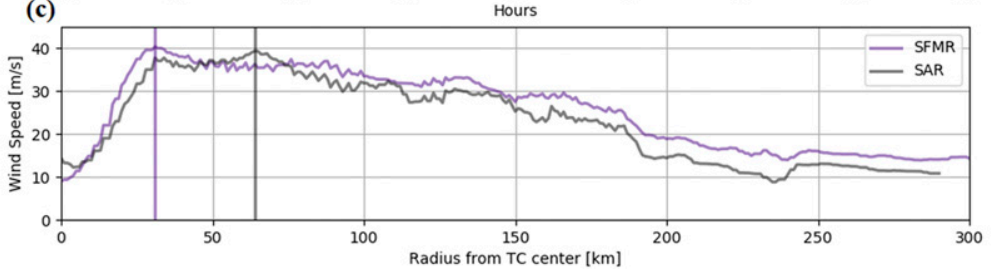

FIG. 8. SFMR- and SAR-derived effective Rmax. (a) SFMR-derived effective Rmax vs SAR-derived effective Rmax. Color code indicates SFMR maximum wind speed. Outliers are within the purple ellipse. (b),(c) Case study of Florence TC on 13 Sep 2018 corresponding to one of the two outliers. (b) Collocated SAR-SFMR measurements along the transect. (c) SFMR-and SAR-derived wind speed profiles and corresponding Rmax. 
(a)
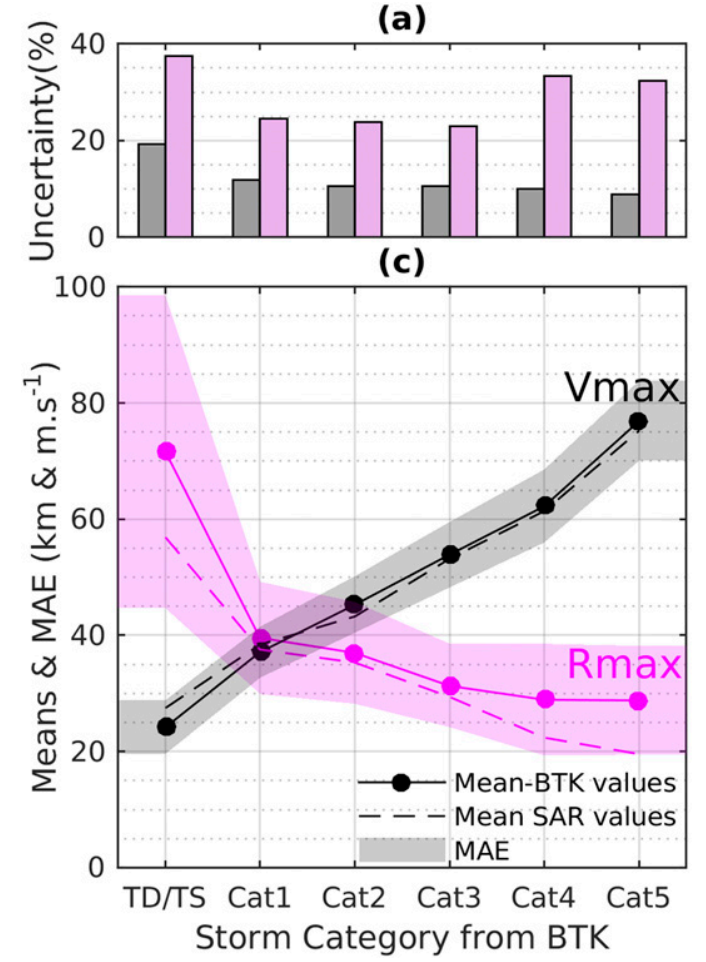

(b)

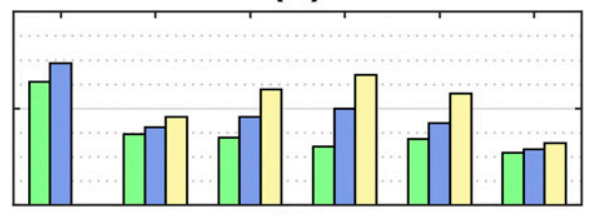

(d)

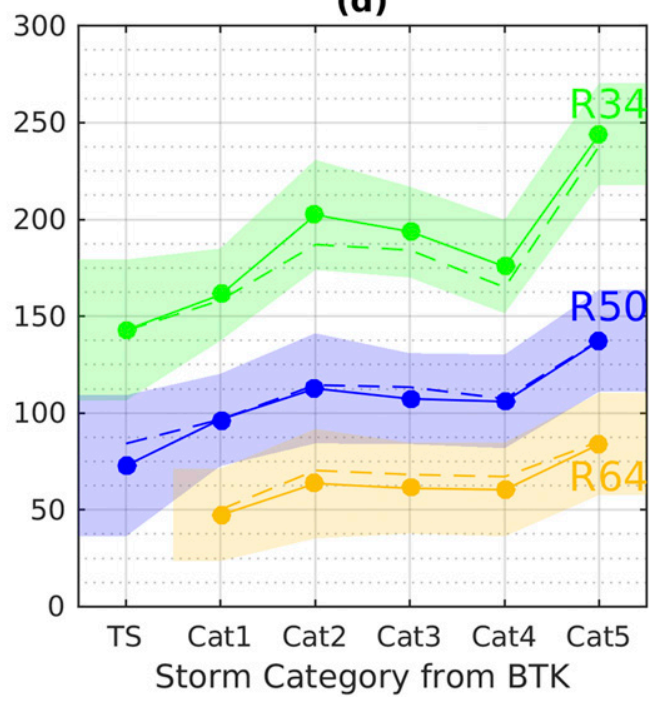

FIG. 9. Best track errors and uncertainties estimated from SAR-derived values for each TC parameter. (left) Inner core (Vmax: black; Rmax: magenta) and (right) wind radii (R34: green; R50: blue; R64: yellow). (a),(b) Histograms of TC parameters uncertainties for each intensity category. Uncertainties are computed as MAE (category)/mean (category). (c),(d) Mean category values are displayed for SAR (dashed colored lines) and best track (solid colored lines); shaded areas outline best track errors computed as mean absolute error (MAE).

Significant differences are found for Rmax mean values and MAE for TD/TS cases and CAT-4/-5 TCs, with Rmax value uncertainties larger than $30 \%$. This confirms the disagreement between SAR and best track Rmax, previously discussed.

For wind structure parameters describing the TC outer core, uncertainties are found to increase with the prescribed wind speed. R64 uncertainties are the largest (peak about 25\%), followed by R50 and R34 uncertainties, regardless the TC intensity. R50 and R64 wind radii uncertainties seem to be storm category dependent, with larger discrepancies obtained for intermediate categories. In particular, R50 and R64 uncertainties peak for CAT-3 TC, with values reaching about $20 \%$ and $25 \%$, respectively. The analysis of best track used in this study further reveals more variability for R50 and R64 from one time step to another for CAT-2 or CAT-3 TCs. This could explain the larger uncertainties when compared to SAR estimates.

Remarkably, all TC parameters suffer from large MAE and uncertainties for TD/TS cases, whereas only Rmax parameter uncertainties rise for major TCs. This deficiency linked to the complexity of weak systems is addressed in section 4. A significant difference in Rmax trends is also found, with a clear plateau for the highest category of best track analysis. It may be indicative of a specific issue regarding Rmax estimates for major TCs. As already mentioned, this apparent lack of sensitivity for Rmax may be due to the low- to mediumresolution observations used to estimate these parameters as well as operational constraints and/or procedures. Our analysis shows differences up to $30 \mathrm{~km}$ when SAR-derived Rmax are about $20 \mathrm{~km}$ (see Fig. 6c). Such cases will be further discussed in section 4.

Our SAR-based results are consistent with previous studies: a range of $10 \%-40 \%$ were found by Knaff and Sampson (2015) and Sampson et al. (2017) for wind structure, and 10\%-20\% by Torn and Snyder (2012) and Landsea and Franklin (2013) for intensity. After averaging estimates over all categories, we end up with the following MAE and uncertainties values for TC parameters: Vmax: [4.8 $\mathrm{m} \mathrm{s}^{-1}$, 9.5\%]; Rmax:[15 km, 32\%]; R64: [14 km, 22\%]; R50: [20 km, 19\%]; and R34: [29 km, 17\%].

\section{Discussion}

\section{a. Best track-SFMR-SAR comparison limitations}

Although comparisons between best track- and SARderived parameters reveal an overall high consistency, both Vmax and wind radii parameters can display noticeable scatter, of about $20 \%$. High-resolution SAR acquisitions using both co- and cross-polarizations are still recent. Current uncertainties governing the relationship between radar parameters and wind speed or rain, as well as possible calibration issues, will certainly improve with increasing systematic 
(a) Madeline 2016-TD(BTK)

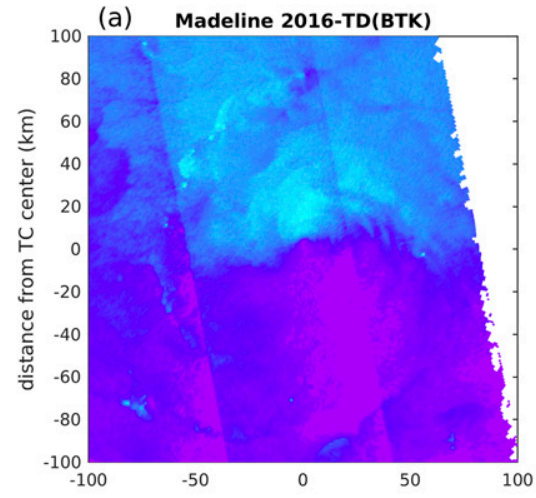

(d) Megi 2016-Cat 3(BTK)

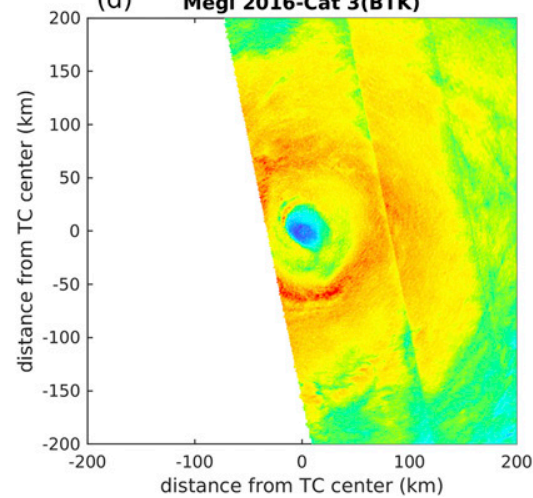

(b)

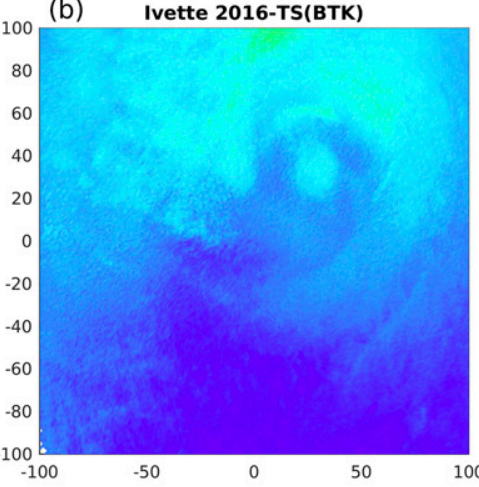

(e) Hector 2018-Cat 4(BTK)

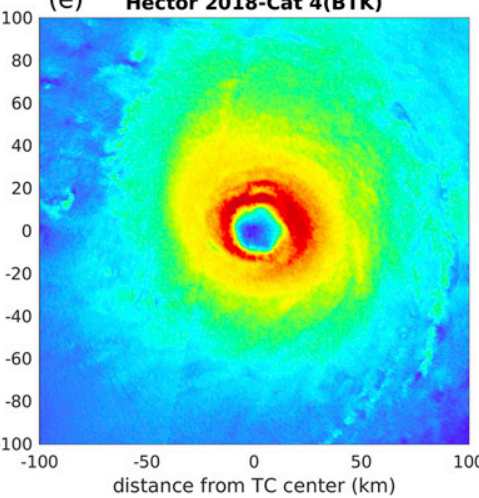

(c) Karl 2016-TD(BTK)
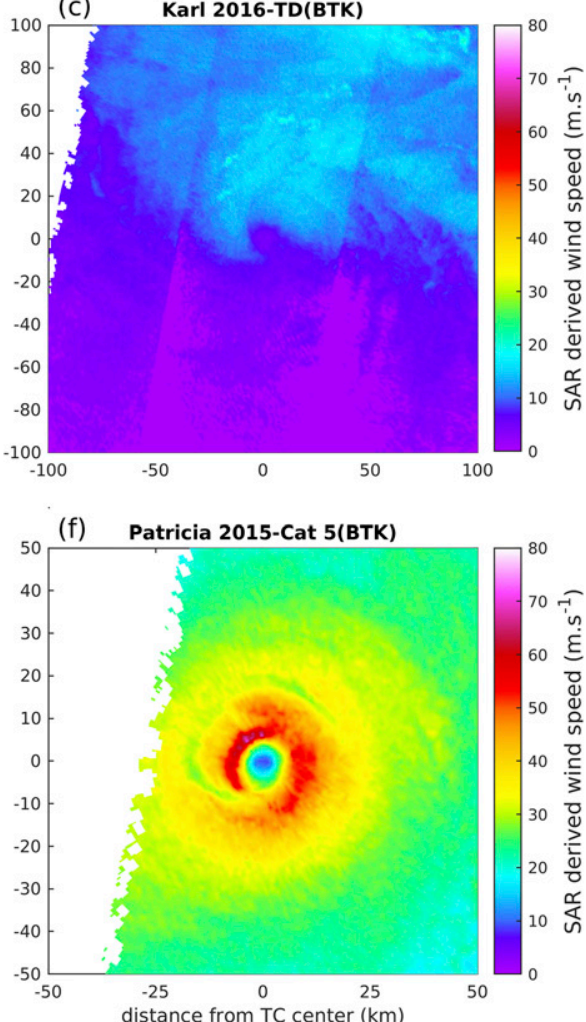

FIG. 10. Mosaic of six specific tropical systems from SAR acquisitions, represented on a polar grid centered at each TC origin. (a),(b) Madeline and Ivette, two weak systems eliminated from analysis due to eye location issues. (c),(d) Two complex structures: (c) Karl, a disorganized TD and (d) Megi, a double-eyewall case. (e),(f) Two intense cases with discrepancies between SAR and BTK: (e) Hector, an open-ocean case without any SFMR measurements, best track-limiting case, and (f) Patricia, a coastline case with SFMR measurements (not for this snapshot), SAR-limiting case. The beam seam effect (signal jump) observed in some panels is induced by the noise floor variation according to incidence angle.

acquisitions. The Vmax difference could be the result of (i) the wind field variability, a SAR acquisition being instantaneous, (ii) the convention used to define Vmax, best track estimates relying on 1-min average wind whereas instantaneous SAR measurements are analyzed at $3 \mathrm{~km}$ resolution, and (iii) the use of indirect methods (e.g., Dvorak) to estimate Vmax values in best track analysis. For wind radii, best track estimates are probably affected by the use of low- to medium-resolution sensors and sensors that signals saturate at higher wind speeds. High-resolution SAR estimates are certainly adequate to assess the sensitivity of TC parameters to resolution, as different spatial resolutions can be considered. As for Vmax, the impact of the wind field variability within $6 \mathrm{~h}$ on wind radii estimates is also certainly a limitation for direct comparisons. The large scatter and associated uncertainties obtained for Rmax, together with the remarkable consistency observed between SAR and SFMR, indicate the need for establishing more robust and homogeneous methodologies for this parameter. Specific comparisons are shown in Fig. 10, further illustrating complex cases and sources of disagreements between SAR and best track analysis.

As shown Figs. 7 and 9, most of the differences regarding the TC wind structure are found for tropical storms or tropical depressions, which exhibit the largest uncertainties compared to other storm categories (see Fig. 9). When only considering wind radii corresponding to TD or TS categories (Vmax $<$ $33 \mathrm{~m} \mathrm{~s}^{-1}$ ), the scatter index and the RMSE obtained for R34 increase from $22 \%$ to $40 \%$ and from 39 to $50 \mathrm{~km}$, respectively, and those obtained for R50 increase from $25 \%$ to $40 \%$ and from 27 to $32 \mathrm{~km}$, respectively. Weaker systems tend to be more asymmetric in their complete radial profile, even in low shear environment (Klotz and Jiang 2017), with a less organized circulation (Fig. 10). TD/TS wind radii (Knaff and Sampson 2015) estimates are thus more difficult to estimate than for hurricanes/typhoons. In addition, at this intensity stage, TD/TS likely do not have an eye structure (Vigh et al. 2012), a constraining situation for our SAR-based methodology. When existing, the eye is often asymmetric ( $\mathrm{Li}$ et al. 2013), a limiting factor for IR-based techniques that require symmetrical eyes (Mueller et al. 2006; Kossin et al. 2007). Such techniques are also sensitive to the cirrus darkening effect, especially in weak eyes or developing eyewall situations (Velden et al. 2006). Regarding the present dataset, seven weak cases (6 TD and 1 TS) were discarded due to unclear eye structure (see Madeline on Fig. 10a). Another noteworthy case corresponds to an unexpected situation, with a high wind area 
measured within the eye region (see Ivette on Fig. 10b). Although likely correct, this case is also removed for the present analysis. After screening, 52 TDs/TSs are included in this study (Fig. 3). The SAR capabilities to examine this range of intensity was already demonstrated in previous studies (Zhang and Perrie 2012). Wind structure can then be used to initialize models to help improving forecast in terms of intensity (Bender et al. 2017), tracks (Kunii 2015) and TC structure (Wu et al. 2010). Low wind speed systems are thus important to precisely describe.

Complex structures also occur during ERC events, for which two distinct wind speed maximum regions can coexist, leading to the existence of double Rmax. During the ERC process, TC goes through significant structural and intensity changes of the inner core, with a widening and phases of weakening and reintensification (Maclay et al. 2008; Kossin and Sitkowski 2012). For instance, Typhoon Megi (2016, WP) encountered this situation, with a first $25 \mathrm{~km}$ Rmax ring and a second one at $60 \mathrm{~km}$ (Fig. 10d), as observed by SAR measurements. In such a case, significant differences on Rmax estimates can be expected if the two applied methods do not pick the same Rmax. Beyond the comparison, an ERC is a critical situation for forecasters, as it changes the TC size with a potential large increase in integrated kinetic energy (Sitkowski et al. 2011). Wind structure is also of paramount importance to assess storm surge (Irish et al. 2008) and many other applications. Rapid intensification may also follow after eyewall replacement [Andrew in 1992; Landsea et al. (2004)], such rapid changes remain challenging for forecasters and those preparing the best track (Leroux et al. 2018). In total, our dataset includes eight observations of ERC, and SAR observations are particularly suitable to infer the double Rmax at finescale (see Fig. 10d) and to possibly guide on the onset or the reached phase of the ERC. This may help forecasters to reduce errors associated with such event (Kossin and DeMaria 2016).

It is also noteworthy that the inner-core wind structures of major TCs are challenging to estimate. When evolving over open ocean, and lacking aircraft data, best track analyses heavily rely on satellite information (Landsea and Franklin 2013). During intensification, Rmax generally tends to decrease, a limiting situation for most of low- to medium-resolution sensors. Hector was one of these small $(\mathrm{Rmax}=16 \mathrm{~km})$ intense systems, developing within the eastern Pacific in 2018 (see Fig. 10e). During its second intensification phase (on 9/10 August 2018), Hector's inner core shrank, and this was not captured by the best track. Rmax was evaluated at $46 \mathrm{~km}$, a large overestimation of about $30 \mathrm{~km}$ (200\% error). Similar examples can be found-notably in east Pacific basin, such as hurricane Ignacio (3 September 2015), for which a $20 \mathrm{~km}$ underestimation was observed. Those significant structure discrepancies can lead to dramatic change in IKE (Powell and Reinhold 2007), and the upper ocean response (Ginis 2002; Kudryavtsev et al. 2019b). Vmax discrepancies also occur during Rapid Intensification (RI) or Rapid Decay (RD) events. For instance, Typhoon Jebi (2018) experienced an explosive increase of $25 \mathrm{~m} \mathrm{~s}^{-1}$ in $24 \mathrm{~h}$. In this particular case, up to $10 \mathrm{~m} \mathrm{~s}^{-1}$ intensity difference is reached between the two sources. Best track analysis may fail due to strong intensity variations (2.5 T maximum; Velden et al. 2006), for which smaller TC cases tend to be more affected $(\mathrm{Xu}$ and Wang 2015; Carrasco et al. 2014; Leroux et al. 2018), possibly combined with the best track binning effect. To note, one limiting situation was found using SAR observations with Hurricane Patricia in 2015 (Fig. 10). Analysis of this powerful TC benefited from temporal and spatial sampling from aircraft, surface and satellites (Rogers et al. 2017). Ocean surface wind speeds, with values as high as $90 \mathrm{~m} \mathrm{~s}^{-1}$ were measured. SAR Vmax estimates only reached $72 \mathrm{~m} \mathrm{~s}^{-1}$, but Rmax corresponded well with observations with the smallest radius of the present dataset $(7 \mathrm{~km})$. Since wind retrievals were performed on a $3 \mathrm{~km}$ resolution grid, the full peak intensity may not have been well resolved. Regardless of this specific case, SAR seems to address most situations to complement the quality of TC parameter estimates. This is especially true for highly variable situations, where $50 \%$ of the values exceeding MAE of both Vmax and Rmax in Figs. $4 \mathrm{~b}$ and $7 \mathrm{~b}$ are defined as fast-evolving cases (including ERC situations). The nature of the highly variable cases is the most limiting factor for SAR-best track comparisons. It is also noted that half of the total adjustments for Vmax, section 3a, were performed for best track estimates identified as highly variable situations for which comparison can be particularly tricky (interpolation failure). For these situations, objective analyses merging microwave and infrared satellites could be used to further investigate these discrepancies between SAR and best track. Those methods include the Satellite Consensus (SATCON; Herndon et al. 2012) product developed by the Cooperative Institute for Meteorological Satellite Studies (CIMSS), or the Multiplatform Tropical Cyclone Surface Wind Analysis (MTCSWA; Knaff et al. 2011) system by the Cooperative Institute for Research in the Atmosphere (CIRA). In particular, because they combine different satellite data sources, they have higher temporal resolution than best track allowing for a more accurate TC intensity variability description, they may provide an interesting complement for further comparisons.

Finally, we also evaluate the impact of the SFMR processing method. As expected from Sapp et al. (2019) and the example presented in section $2 \mathrm{c}$, no matter the product considered, a great consistency is found between SAR and SFMR data. Regarding wind speed parameter, the RMSE and correlation remain very similar, whereas the largest differences are obtained for the bias. Correlation coefficients are 0.93 and 0.92 for AOML/HRD and NOAA/NESDIS processing methods, respectively. RMSE are 4.32 and $3.86 \mathrm{~m} \mathrm{~s}^{-1}$ for AOML/HRD and NOAA/NESDIS, respectively. Values for bias are different: 1.49 and $-0.24 \mathrm{~m} \mathrm{~s}^{-1}$ for AOML/HRD and NOAA/NESDIS, respectively. Regarding Rmax parameters, differences are negligible. When comparing the two processing versions, correlation is higher than 0.90, RMSE lower than $4 \mathrm{~km}$ and a bias around $0 \mathrm{~km}$. Further comparing the two SFMR processing versions is clearly out of the scope of this study and the choice of SFMR product does not impact our conclusions on SAR-best track comparisons. In particular the main result concerns Rmax parameter for which the consistency between SAR and best track is dramatically improved when SFMR measurements are 


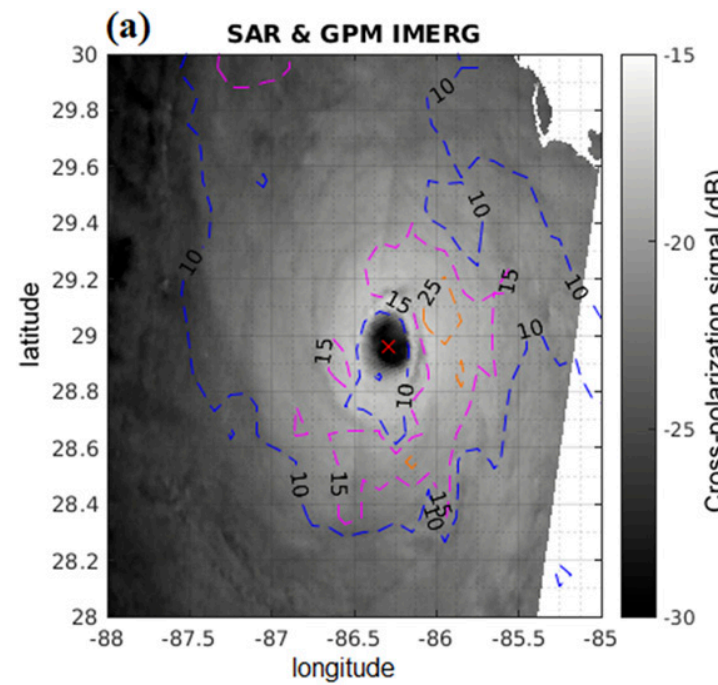

(b) NEXRAD weather radar

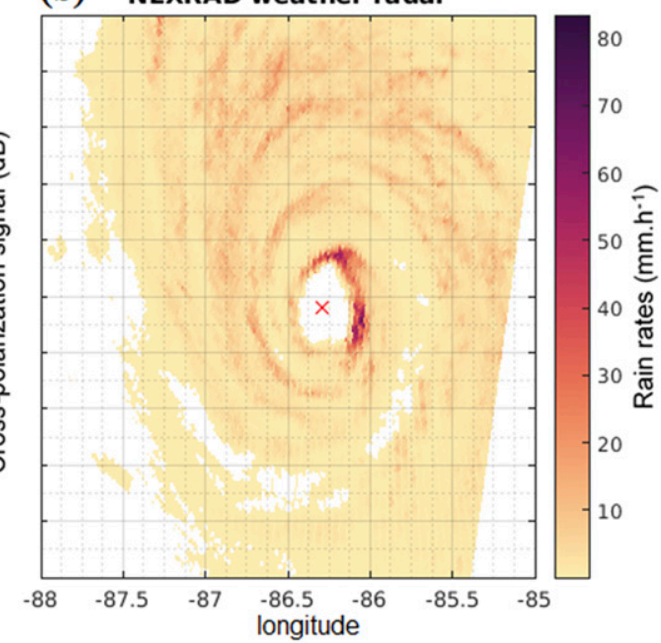

FIG. 11. Comparison of two rain products for the Hurricane Michael case on 10 Oct 2018. (a) Cross-polarization signal of Sentinel-1A with rain-rate contours of GPM IMERG $\left(\mathrm{mm} \mathrm{h}^{-1}\right)$. (b) NEXRAD base reflectivity converted to $\mathrm{mm} \mathrm{h}^{-1}$.

available. And the processing version of SFMR does not impact the location of the strongest wind speeds along the transects. In contrast, the SFMR impact on SAR-best track comparison for Vmax parameter is found to be negligible.

\section{b. Rain impact on $S A R$}

Although SAR measurements appear relevant to provide guidance in many limiting situations, specific processing steps are still required to provide qualified estimates (see section 3). Specifically, a special method was developed to remove rain effects for wind estimates. This is important because rain can cause both increase and/or decrease of C-band backscatter signals (Katsaros et al. 2000; Alpers et al. 2016). This results from either modification of the ocean surface waves, damping and enhancement of the roughness by rain droplets impinging the surface, or from direct interactions with hydrometeors (scattering or attenuation) in the atmosphere column along the path of the electromagnetic waves.

For the present database, rain rate estimates are systematically inferred from IMERG product, collocated in time and space with SAR acquisitions. The rain intensity for a given TC is defined by the mean rain rate $\left(\mathrm{mm} \mathrm{h}^{-1}\right)$, estimated on a $\pm 10 \mathrm{~km}$ ring around SAR-derived Rmax. In the case of CAT-1 and higher TC, heavy rain occurrence is defined by mean rain rates larger than $30 \mathrm{~mm} \mathrm{~h}^{-1}$. This threshold is lowered for TD/TS to $10 \mathrm{~mm} \mathrm{~h}^{-1}$. Applying these criteria, $70(42 \%)$ cases correspond to heavy rainfall, and 23 of them (1/3) were found to be significantly affected by rain. As briefly mentioned in section 3, a case is considered significantly affected by rain, if an anomalous peak is found in the SAR-derived Vmax azimuthal distribution, and can be associated to heavy rainfall as indicated by IMERG. To help distinguish several maxima, we use the Jelesniansky description [Jelesnianski (1966), detailed in
Pan et al. (2016)], taking into account the TC translation induced Vmax asymmetry.

When applied, this procedure improves consistency between SAR and best track (Fig. 4a). However, four remaining cases exhibit anomalous peaks in the Vmax azimuthal distribution, for which the heavy rainfall criterion derived from IMERG is not met. Figure 11 illustrates one of these cases, Hurricane Michael (2018). In Michael, IMERG measurements barely reach $25 \mathrm{~mm} \mathrm{~h}^{-1}$. In contrast, the high reflectivity measurements by the KEVX radar (from NEXRAD network) around the eyewall tend to indicate heavy rainfall $[>50 \mathrm{db} Z$, corresponding to about $80 \mathrm{~mm} \mathrm{~h}^{-1}$ using $Z(R)$ relation from Fulton et al. (1998)] that was not captured by IMERG. This case demonstrates the limitation of using medium-resolution rain products such as IMERG, for both time and space sampling, $30 \mathrm{~min}$ and $0.1^{\circ}$, respectively. In fact, rain rate is often related with maximum wind intensity (Lin et al. 2015), and its variability (Rodgers and Adler 1981) with maximum activity generally located in the inner TC core (Lin et al. 2015; Jiang et al. 2008). In this deep convective region, the diameter of rain cores can be smaller than IMERG resolution $(\sim 5-10 \mathrm{~km})$, with rain rate exceeding $20 \mathrm{~mm} \mathrm{~h}^{-1}$ (Begum and Otung 2009). Highresolution weather radar $(1 \mathrm{~km})$ can capture this activity. Among the 17 cases collocated with NEXRAD, four additional heavy rain cases like the Michael case were found. $70 \%$ of the adjusted SAR-derived Vmax estimates correspond to cases with impacting heavy rainfall, yielding mean adjustments of $6.2 \mathrm{~m} \mathrm{~s}^{-1}\left(4.5 \mathrm{~m} \mathrm{~s}^{-1}\right.$ for hurricanes and $8.1 \mathrm{~m} \mathrm{~s}^{-1}$ for TDs and TSs). This confirms that intense rain is the most limiting factor to retrieve Vmax from C-band SAR measurements. Interestingly, SAR-derived Rmax are generally quite insensitive to rain issues for hurricane-force situations where rain-induced ambiguities are close to the region of maximum winds and rather symmetric. However, for five TDs, SAR backscattered signal enhancement associated with outer rainband activity, can compete with the 
(a)

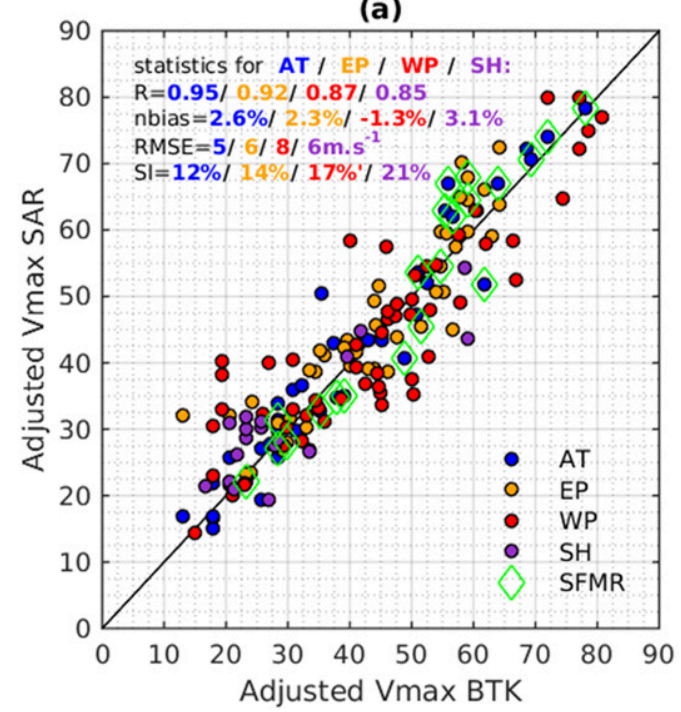

(b)

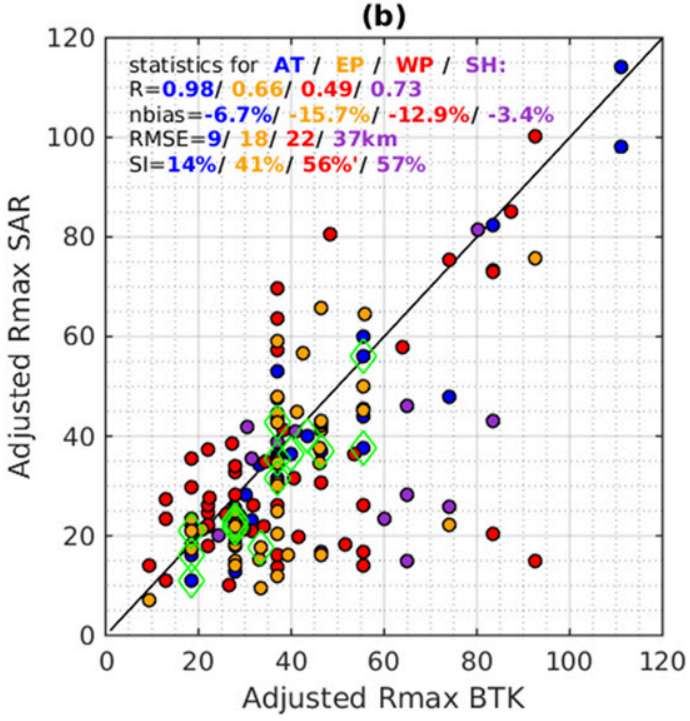

FIG. 12. Interbasin comparison of inner-core parameters. As in Figs. $4 \mathrm{~b}$ and $7 \mathrm{~b}$, but with respect to basin location. Cases with simultaneous SFMR measurements are framed with green diamond. Statistics are added for each basin.

weak TD wind signature (e.g., Karl in Fig. 10). Still, the global impact on Rmax determination is generally minimal.

\section{c. Discrepancies among TC basins}

Due to its global coverage and unique high resolution, SAR can also assess TC parameter variability and document the best track quality homogeneity for both inner and outer core, among different ocean basins. TC characteristics regarding size, intensity and trajectory (Chavas et al. 2016), as well as best track quality (Landsea and Franklin 2013), also depend on ocean basin. In particular, improved performances are achieved when aircraft reconnaissance and SFMR measurements are available (Landsea and Franklin 2013; Sampson et al. 2018). Figure 12 shows Vmax and Rmax comparisons as function of basin location and SFMR coverage. TD cases are not considered for this interbasin comparison, as none of them benefited from SFMR observations. To note, unlike in section 3, we do not compare direct SFMR information but rather best track analyses that are influenced by SFMR measurements. Inherent smoothing in the best track analysis may slightly reduce the correlation presented in Fig. 8. Still the benefit of using SFMR is obvious for both Vmax and Rmax parameters (see Fig. 12) with improved agreement between SAR and best track when SFMR observations are available. As listed in Table 1, this especially applies for R50, R64 and Rmax wind structure parameters. Only R34 parameters are found to be very similar. This certainly reflects the use of scatterometer measurements to improve R34 estimates for best track (Brennan et al. 2009).

Regarding performances for each individual basin (Fig. 12), the North Atlantic basin logically experiences higher consistency with SAR $(R>0.90)$, thanks to SFMR observations. Similar performances for TC intensity are obtained in the east Pacific $(R=0.91)$. Overall, and despite a slight decay for nonU.S. basins, Vmax performances are found very robust for all basins. Significant discrepancies between basins primarily exist for Rmax. More specifically, east Pacific undergoes the strongest normalized bias $(-16 \%)$. This is likely associated to the prominence of smaller storms (Chavas et al. 2016; Chan and Chan 2012) combined with a general lack of aircraft data in this basin. In addition, those small systems appear to experience higher RI/RD rate (Carrasco et al. 2014; Xu and Wang 2015), making TCs developing in the east Pacific more temporally variable. For the west Pacific basin, a larger distribution of TC sizes (Chavas et al. 2016), together with the largest systems observed (Knaff et al. 2014) is expected. This, combined with an absence of SFMR measurements, may explain the large RMSE and scatter in estimates. Likewise, the Southern Hemisphere ( $\mathrm{SH})$ shows large scatter. However, the small number of available cases in the present dataset prevents any strong and definitive conclusions. To note, specific adjustments are applied to the initial Dvorak analysis scheme by each RSMC, with respect to their measurements capabilities (Velden et al. 2017) and performances could be different than those obtained here as we are only using the JTWC analysis. Furthermore, Southern Hemisphere never benefits from SFMR measurements. This can explain the low consistency achieved for Vmax.

\section{Conclusions and prospects}

Thanks to an unprecedented large dataset, consisting of 161 acquisitions from three different SAR instruments ( $R S 2$, $S 1 A / B)$, SAR observations are shown to not only explore the full spectrum of TC intensities, but also to precisely detail TC structure parameters from wind radii well removed from the eyewall region to the location of the maximum wind and $\mathrm{Rmax}$ in small TCs. Rmax is a parameter of paramount importance for the assessment and forecasting of ocean-atmosphere interactions, damages (Powell and Reinhold 2007), storm surge 
TABLE 1. Mean absolute errors and uncertainties in parentheses of each TC parameter according to presence of SFMR information.

\begin{tabular}{lcrrrr}
\hline \hline & Vmax $\left(\mathrm{m} \mathrm{s}^{-1}\right)$ & $R \operatorname{Rax}(\mathrm{km})$ & $\mathrm{R} 34(\mathrm{~km})$ & $\mathrm{R} 50(\mathrm{~km})$ & $\mathrm{R} 64(\mathrm{~km})$ \\
\hline BTK $_{\text {SFMR }}$ & $4.0(8 \%)$ & $6.0(18 \%)$ & $26.5(15 \%)$ & $12.3(12.8 \%)$ & $9.5(15 \%)$ \\
BTK $_{\text {NoSFMR }}$ & $5.1(13 \%)$ & $16.5(33 \%)$ & $30.0(17 \%)$ & $21.6(20 \%)$ & $16.0(26 \%)$ \\
\hline
\end{tabular}

(Irish et al. 2008), and also to initialize parametric models (Holland 1980; Wood et al. 2013; Willoughby and Rahn 2004). In addition to the potential to resolve the complete wind field (Fig. 1), SAR measurements are found fully consistent with SFMR $(R>0.9)$. SAR acquisitions can be performed everywhere, independent of TC basin and best track. Although an acquisition scheme methodology is required (see section 2), comparisons (see section 3) highlight the ability of SAR to routinely guide analysis, especially in limiting situations, where significant variability is noticed and jeopardize best track estimates (50\% of discrepancies).

As previously reported (Horstmann et al. 2013, 2015), SAR signals still require special processing steps and screening before being used to infer TC parameters, especially Vmax estimates made in heavy rain conditions. Here we have shown that heavy rain possibly account for $20 \%$ of observed scatter of Vmax (Fig. 4a). More dedicated efforts are certainly required, with use of IMERG products, GPM's satellite measurements, weather ground-based radar, or other satellite-based product such as MIMIC (Wimmers and Velden 2007) to provide bestqualified Vmax estimates. Following the steps detailed in this paper, high-quality Vmax estimates can be obtained with respect to both SFMR $(R=0.91)$ and best track $(R=0.92)$. Unlike Vmax, Rmax estimates appear only weakly affected by heavy precipitation, leading to almost perfect agreement with $\operatorname{SFMR}(R=0.98)$. More significant discrepancies in Rmax and Vmax comparisons with best track occur when storms are evolving quickly or when there are double Rmax structures (Fig. 7). We also observe that wind radii uncertainties increase with TC intensity (Fig. 9). Since temporal variability has an impact on best track wind structure estimates (50\%), the lack of more direct methods seems to be the most impactful to the results of our study. These impacts are highlighted by comparing performances over different TC basins: highest scores are obtained for the Atlantic basin, which benefits from good SFMR coverage ( $70 \%$ of our TC cases). Likewise, R34 was found very consistent regardless of TC basins or SFMR available observations (Table 1), which highlights the real benefit of using scatterometer measurements in best track analysis.

This apparent reliance on scatterometry implies that TC wind structure analyses could immediately benefit from the new capabilities of the recent generation of rain-free L-band passive radiometer sensors: SMAP/SMOS that depict TC, still at the low resolution of $50 \mathrm{~km}$, but with a wide swath and twicedaily temporal coverage (Reul et al. 2016, 2017). In such a context, SMAP measurements have been recently added to ATCF (JTWC 2017). It has been shown that the coarse resolution of these observations generally precludes direct estimation of the inner-core parameters for TCs with Rmax less than $40 \mathrm{~km}$ (most of cases $\geq \mathrm{CAT}-2$; see Fig. 9). But these satellites can provide very accurate wind radii that have been found to be in good agreement with both SAR (Mouche et al. 2017; Zhao et al. 2018) and SFMR (Reul et al. 2016; Meissner et al. 2017) estimates. Today, the SMOS/SMAP constellation, possibly augmented by AMSR-2 measurements, combined with the unique capability of SAR to inform the eyewall region, offer quite unique opportunities. In addition, the CYGNSS constellation with its high temporal resolution and insensitivity to high rain rates (Ruf et al. 2016; Morris and Ruf 2017) can also be an asset to complement SAR measurements, especially in situation of heavy rain conditions.

As shown here, improved TC parameter estimates can be robustly derived using SAR winds corrected for heavy rainfall to lower errors associated to more indirect and subjective analysis methods. However, to date, no MDA-operating RadarSat-2 or Copernicus/ESA-operating Sentinel-1 ensures any operational service to systematically acquire data over TC and then process and disseminate them into wind field in nearreal time. The new version of 3-hourly IBTraCs (Knapp et al. 2018) and annual best track preparation at NHC and JTWC may benefit from this growing combined capability using these different sensors in the future. It will bring finer description of TC evolution and wind field variability that should directly benefit operational, applied and/or research communities. Presently, best track uncertainties appear to largely depend on the availability of SFMR information (Table 1), leading to large discrepancies between basins (Fig. 12). Our results have also shown that best track errors are in agreement with previous studies (Torn and Snyder 2012; Landsea and Franklin 2013; Knaff and Sampson 2015): 10\% uncertainties for intensity and $20 \%$ for wind radii (section 3 ). More importantly, uncertainties for Rmax, which we found to be $32 \%$, were not previously assessed. Clearly, SAR observations can thus guide poststorm analysis of this important parameter, which is not yet reanalyzed as part of the best track process. In a future study, SATCON (Velden and Herndon 2020) and MTCSWA analysis products may be considered to extend this work. Their higher temporal resolution and the use of recent methods, like specific microwave algorithms (Wimmers and Velden 2016) can be an alternate source of comparison, notably for Rmax and complex situation such as ERC event. Furthermore, these methods are generally based on $89-91 \mathrm{GHz}$ microwave radiometers that provide elevated eye features and midlevel winds (MTCSWA). A joint use of C-Band SAR and $89-91 \mathrm{GHz}$ microwave radiometers could allow estimates of the vertical eyewall slope and possibly lead to additional guidance in the surface adjustment to be performed. Finally, SAR measurements can also document the TC eye dynamics ( $\mathrm{Li}$ et al. 2013), and provide high-resolution details of the nature of the TC's wind field. Thanks to the growing database, future investigations will be conducted to more carefully analyze the TC's finer-scale wind structures, to not only provide details of the 
radial and azimuthal wind variations, but details of the organization of large eddies that occur at various spatial scales (Foster 2005) within the TC.

Acknowledgments. The SHOC initiative has been possible thanks to SAR data access supported by ESA Sentinel-1 mission ground segment team and GIS BreTel. In particular, the implication of L. Martino, P. Potin, Y.-L. Desnos, and M. Engdhal at ESA and the whole Sentinel-1 mission planning team have been decisive. Authors also acknowledge Joe Sapp (NOAA/NESDIS) for SFMR data, R. Husson (CLS), F. Said (NOAA/NESDIS), and S. Jullien (IFREMER) for technical support during SHOC, K. Cordier from Sentinel-1 Mission Performance Center for providing Sentinel-1 data processed with IPF version 2.90 (or higher), Nuno Miranda (ESA) for support with Sentinel-1 data, and Olivier Archer (IFREMER) for his mastering of Nephelea computer system. J. Knaff thanks NOAA/Center for Satellite Applications and Research for providing the time work on this subject. The views, opinions, and findings contained in this report are those of the authors and should not be construed as an official National Oceanic and Atmospheric Administration or U.S. government position, policy, or decision. This study contains modified Copernicus Sentinel-1 (2016-18) and RadarSat-2 data. Sentinel-1 is part of the European space component of the Copernicus European program. Data are free of charge and available on the Copernicus Open Access Hub (https://scihub.copernicus.eu/). RadarSat-2 is a commercial mission and data are provided by MDA's Geospatial Services (https:/mdacorporation.com/ geospatial/international). Access to RadarSat-2 data was supported by public funds (Ministère de l'Education Nationale, de l'Enseignement Supérieur et de la Recherche, FEDER, Région Bretagne, Conseil Général du Finistère, Brest Métropole) and by Institut Mines Télécom, received in the framework of the VIGISAT project managed by "Groupement Bretagne Télédétection" (GIS BreTel-Brittany Remote Sensing). The NEXRAD and hurricane track products are archived by the National Centers for Environmental Information and available via FTP download (http://www.ncdc.noaa.gov/nexradinv/ choosesite.jsp) and IBTrACS website (https://www.ncdc. noaa.gov/ibtracs/). SFMR and combined satellite aircraft analysis products are provided by NOAA/NESDIS team, respectively, at https://manati.star.nesdis.noaa.gov/SFMR/1.0/ and http://rammb.cira.colostate.edu/products/tc_realtime/ index.asp. This work was partly supported by CNES TOSCA program (COWS project), by European Space Agency through CYMS project (Contract No. 4000129822/19/I-DT), Sentinel-1 A Mission Performance Center (Contract No. 4000107360/12/I-LG), EUMETSAT CHEF project, ANR (FEM) CARAVELE project.

\section{REFERENCES}

Alpers, W., B. Zhang, A. Mouche, K. Zeng, and P. W. Chan, 2016: Rain footprints on C-band synthetic aperture radar images of the ocean-Revisited. Remote Sens. Environ., 187, 169-185, https://doi.org/10.1016/j.rse.2016.10.015.

Banal, S., S. Iris, and R. Saint-Jean, 2007: Canadian Space Agency's hurricane watch program: Archive contents, data access and improved planning strategies. 2007 IEEE Int. Geoscience and Remote Sensing Symp., Barcelona, Spain, IEEE, 3494-3497, https://doi.org/10.1109/IGARSS.2007.4423599.

Begum, S., and I. E. Otung, 2009: Rain cell size distribution inferred from rain gauge and radar data in the UK. Radio Sci., 44, RS2015, https://doi.org/10.1029/2008RS003984.

Bender, M. A., T. P. Marchok, C. R. Sampson, J. A. Knaff, and M. J. Morin, 2017: Impact of storm size on prediction of storm track and intensity using the 2016 operational GFDL hurricane model. Wea. Forecasting, 32, 1491-1508, https://doi.org/ 10.1175/WAF-D-16-0220.1.

Brennan, M. J., C. C. Hennon, and R. D. Knabb, 2009: The operational use of QuikSCAT ocean surface vector winds at the National Hurricane Center. Wea. Forecasting, 24, 621-645, https://doi.org/10.1175/2008WAF2222188.1.

Carrasco, C. A., C. W. Landsea, and Y.-L. Lin, 2014: The influence of tropical cyclone size on its intensification. Wea. Forecasting, 29, 582-590, https://doi.org/10.1175/WAF-D-13-00092.1.

Chan, K. T. F., and J. C. L. Chan, 2012: Size and strength of tropical cyclones as inferred from QuikSCAT data. Mon. Wea. Rev., 140, 811-824, https://doi.org/10.1175/MWR-D-10-05062.1.

Chavas, D. R., and N. Lin, 2016: A model for the complete radial structure of the tropical cyclone wind field. Part II: Wind field variability. J. Atmos. Sci., 73, 3093-3113, https://doi.org/ 10.1175/JAS-D-15-0185.1.

,$--\longrightarrow$, and K. Emanuel, 2015: A model for the complete radial structure of the tropical cyclone wind field. Part I: Comparison with observed structure. J. Atmos. Sci., 72, 3647-3662, https:// doi.org/10.1175/JAS-D-15-0014.1.

,,$-- W$. Wong, and Y. Lin, 2016: Observed tropical cyclone size revisited. J. Climate, 29, 2923-2939, https://doi.org/ 10.1175/JCLI-D-15-0731.1.

DeMaria, M., and Coauthors, 2013: Improvements to the operational tropical cyclone wind speed probability model. Wea. Forecasting, 28, 586-602, https://doi.org/10.1175/WAF-D-12-00116.1.

Demuth, J. L., M. DeMaria, J. A. Knaff, and T. H. Vonder Haar, 2004: Evaluation of Advanced Microwave Sounding Unit tropicalcyclone intensity and size estimation algorithms. J. Appl. Meteor., 43, 282-296, https://doi.org/10.1175/1520-0450(2004)043\% 3C0282:EOAMSU\%3E2.0.CO;2.

,$- \ldots$, and _ 2006: Improvement of Advanced Microwave Sounding Unit tropical cyclone intensity and size estimation algorithms. J. Appl. Meteor. Climatol., 45, 1573-1581, https:// doi.org/10.1175/JAM2429.1.

Fang, H., T. Xie, W. Perrie, G. Zhang, J. Yang, and Y. He, 2018: Comparison of C-band quad-polarization synthetic aperture radar wind retrieval models. Remote Sens., 10, 1448, https:// doi.org/10.3390/rs10091448.

Foster, R. C., 2005: Why rolls are prevalent in the hurricane boundary layer. J. Atmos. Sci., 62, 2647-2661, https://doi.org/ 10.1175/JAS3475.1.

Fulton, R. A., J. P. Breidenbach, D.-J. Seo, D. A. Miller, and T. O'Bannon, 1998: The WSR-88D rainfall algorithm. Wea. Forecasting, 13, 377-395, https://doi.org/10.1175/1520-0434(1998) $013<0377$ :TWRA $>2.0$. CO;2.

Geisler, J. E., 1970: Linear theory of the response of a two layer ocean to a moving hurricane. Geophys. Fluid Dyn., 1, 249-272, https://doi.org/10.1080/03091927009365774.

Ginis, I., 2002: Tropical cyclone-ocean interactions. Advances in Fluid Mechanics IV, C. A. Brebbia, M. Rahman, and R. Verhoeven, Eds.,WIT Press, 83-114.

Herndon, D. C., C. S. Velden, and J. D. Hawkins, 2012: Update on SATellite-based CONsensus (SATCON) approach to 
TC intensity estimation. 30th Conf. on Hurricanes and Tropical Meteorology, Ponte Vedra, FL, Amer. Meteor. Soc., 7C.2, https://ams.confex.com/ams/30Hurricane/webprogram/ Paper205129.html.

Holland, G. J., 1980: An analytic model of the wind and pressure profiles in hurricanes. Mon. Wea. Rev., 108, 1212-1218, https://doi.org/10.1175/1520-0493(1980)108\%3C1212:AAMOTW $\% 3 \mathrm{E} 2.0 . \mathrm{CO} ; 2$.

Horstmann, J., C. Wackerman, S. Falchetti, and S. Maresca, 2013: Tropical cyclone winds retrieved from synthetic aperture radar. Oceanography, 26, 46-57, https://doi.org/ 10.5670/oceanog.2013.30.

—, S. Falchetti, C. Wackerman, S. Maresca, M. J. Caruso, and H. C. Graber, 2015: Tropical cyclone winds retrieved from C-band cross-polarized synthetic aperture radar. IEEE Trans. Geosci. Remote Sens., 53, 2887-2898, https://doi.org/10.1109/ TGRS.2014.2366433.

Huffman, G. J., and Coauthors, 2019: Algorithm Theoretical Basis Document (ATBD) version 06: NASA Global Precipitation Measurement (GPM) Integrated Multi-satellite Retrievals for GPM (IMERG). NASA, 38 pp., https://gpm.nasa.gov/sites/ default/files/document_files/IMERG_ATBD_V06_0.pdf.

Irish, J. L., D. T. Resio, and J. J. Ratcliff, 2008: The influence of storm size on hurricane surge. J. Phys. Oceanogr., 38, 20032013, https://doi.org/10.1175/2008JPO3727.1.

Jelesnianski, C. P., 1966: Numerical computations of storm surges without bottom stress. Mon. Wea. Rev., 94, 379-394, https:// doi.org/10.1175/1520-0493(1966)094\%3C0379:NCOSSW\% 3E2.3.CO;2.

Jiang, H., J. B. Halverson, J. Simpson, and E. J. Zipser, 2008: Hurricane "rainfall potential" derived from satellite observations aids overland rainfall prediction. J. Appl. Meteor. Climatol., 47, 944-959, https://doi.org/10.1175/2007JAMC1619.1.

Jorgensen, D. P., 1984: Mesoscale and convective-scale characteristics of mature hurricanes. Part II: Inner core structure of Hurricane Allen (1980). J. Atmos. Sci., 41, 1287-1311, https:// doi.org/10.1175/1520-0469(1984)041\%3C1287:MACSCO \% 3E2.0.CO;2.

JTWC, 2017: Annual Tropical Cyclone Report 2017. JTWC Tech. Rep., JTWC, 133 pp., https://www.metoc.navy.mil/ jtwc/products/atcr/2017atcr.pdf.

Katsaros, K., P. W. Vachon, P. Black, P. Dodge, and E. Uhlhorn, 2000: Wind fields from SAR: Could they improve our understanding of storm dynamics? Government of Canada, https:// doi.org/10.4095/219617.

Klotz, B. W., and E. W. Uhlhorn, 2014: Improved stepped frequency microwave radiometer tropical cyclone surface winds in heavy precipitation. J. Atmos. Oceanic Technol., 31, 2392-2408, https://doi.org/10.1175/JTECH-D-14-00028.1.

_ , and H. Jiang, 2017: Examination of surface wind asymmetries in tropical cyclones. Part I: General structure and wind shear impacts. Mon. Wea. Rev., 145, 3989-4009, https://doi.org/ 10.1175/MWR-D-17-0019.1.

Knaff, J. A., and C. R. Sampson, 2015: After a decade are Atlantic tropical cyclone gale force wind radii forecasts now skillful? Wea. Forecasting, 30, 702-709, https://doi.org/ 10.1175/WAF-D-14-00149.1.

,,- M. DeMaria, T. P. Marchok, J. M. Gross, and C. J. McAdie, 2007: Statistical tropical cyclone wind radii prediction using climatology and persistence. Wea. Forecasting, 22, 781-791, https://doi.org/10.1175/WAF1026.1.

—_, M. DeMaria, D. A. Molenar, C. R. Sampson, and M. G. Seybold, 2011: An automated, objective, multiple-satellite-platform tropical cyclone surface wind analysis. J. Appl. Meteor. Climatol., 50, 2149-2166, https://doi.org/10.1175/2011JAMC2673.1.

, C. R. Sampson, J. E. Peak, J. Cummings, and W. H. Schubert, 2013: Upper oceanic energy response to tropical cyclone passage. J. Climate, 26, 2631-2650, https://doi.org/ 10.1175/JCLI-D-12-00038.1.

- S. P. Longmore, and D. A. Molenar, 2014: An objective satellite-based tropical cyclone size climatology. J. Climate, 27, 455-476, https://doi.org/10.1175/JCLI-D-13-00096.1.

, R. T. DeMaria, and D. A. Molenar, 2015: Improved tropical-cyclone flight-level wind estimates using routine infrared satellite reconnaissance. J. Appl. Meteor. Climatol., 54, 463-478, https://doi.org/10.1175/JAMC-D-14-0112.1.

—, C. J. Slocum, K. D. Musgrave, C. R. Sampson, and B. R. Strahl, 2016: Using routinely available information to estimate tropical cyclone wind structure. Mon. Wea. Rev., 144, 1233-1247, https://doi.org/10.1175/MWR-D-15-0267.1.

Knapp, K. R., M. C. Kruk, D. H. Levinson, H. J. Diamond, and C. J. Neumann, 2010: The International Best Track Archive for Climate Stewardship (IBTrACS). Bull. Amer. Meteor. Soc., 91, 363-376, https://doi.org/10.1175/2009BAMS2755.1.

— H. J. Diamond, J. P. Kossin, M. C. Kruk, and C. J. Schreck, 2018: International Best Track Archive for Climate Stewardship (IBTrACS) Project, version 4. NOAA, accessed December 2019, https://doi.org/10.25921/82ty-9e16.

Koch, W., 2004: Directional analysis of SAR images aiming at wind direction. IEEE Trans. Geosci. Remote Sens., 42, 702-710, https://doi.org/10.1109/TGRS.2003.818811.

Kossin, J. P., and M. Sitkowski, 2012: Predicting hurricane intensity and structure changes associated with eyewall replacement cycles. Wea. Forecasting, 27, 484-488, https://doi.org/10.1175/ WAF-D-11-00106.1.

—_, and M. DeMaria, 2016: Reducing operational hurricane intensity forecast errors during eyewall replacement cycles. Wea. Forecasting, 31, 601-608, https://doi.org/10.1175/ WAF-D-15-0123.1.

$\longrightarrow$, J. A. Knaff, H. I. Berger, D. C. Herndon, T. A. Cram, C. S. Velden, R. J. Murnane, and J. D. Hawkins, 2007: Estimating hurricane wind structure in the absence of aircraft reconnaissance. Wea. Forecasting, 22, 89-101, https://doi.org/ 10.1175/WAF985.1.

Kruk, M. C., K. R. Knapp, and D. H. Levinson, 2010: A technique for combining global tropical cyclone best track data. J. Atmos. Oceanic Technol., 27, 680-692, https://doi.org/ 10.1175/2009JTECHA1267.1.

Kudryavtsev, V., P. Golubkin, and B. Chapron, 2015: A simplified wave enhancement criterion for moving extreme events. J. Geophys. Res. Oceans, 120, 7538-7558, https://doi.org/ 10.1002/2015JC011284.

- A. Monzikova, C. Combot, B. Chapron, and N. Reul, 2019a: A simplified model for the baroclinic and barotropic ocean response to moving tropical cyclones: 2 . Model and simulations. J. Geophys. Res. Oceans, 124, 3462-3485, https://doi.org/ 10.1029/2018JC014747.

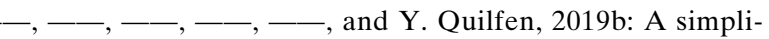
fied model for the baroclinic and barotropic ocean response to moving tropical cyclones: 1 . Satellite observations. J. Geophys. Res. Oceans, 124, 3446-3461, https://doi.org/ 10.1029/2018JC014746.

Kunii, M., 2015: Assimilation of tropical cyclone track and wind radius data with an ensemble Kalman filter. Wea. Forecasting, 30, 1050-1063, https://doi.org/10.1175/WAFD-14-00088.1. 
Lajoie, F., and K. Walsh, 2008: A technique to determine the radius of maximum wind of a tropical cyclone. Wea. Forecasting, 23, 1007-1015, https://doi.org/10.1175/2008WAF2007077.1.

Landsea, C. W., and J. L. Franklin, 2013: Atlantic hurricane database uncertainty and presentation of a new database format. Mon. Wea. Rev., 141, 3576-3592, https://doi.org/ 10.1175/MWR-D-12-00254.1.

— , and Coauthors, 2004: A reanalysis of Hurricane Andrew's intensity. Bull. Amer. Meteor. Soc., 85, 1699-1712, https:// doi.org/10.1175/BAMS-85-11-1699.

Leroux, M.-D., J. Meister, D. Mekies, A.-L. Dorla, and P. Caroff, 2018: A climatology of southwest Indian Ocean tropical systems: Their number, tracks, impacts, sizes, empirical maximum potential intensity, and intensity changes. J. Appl. Meteor. Climatol., 57, 1021-1041, https://doi.org/10.1175/ JAMC-D-17-0094.1.

Li, X., J. A. Zhang, X. Yang, W. G. Pichel, M. DeMaria, D. Long, and Z. Li, 2013: Tropical cyclone morphology from spaceborne synthetic aperture radar. Bull. Amer. Meteor. Soc., 94, 215-230, https://doi.org/10.1175/BAMS-D-11-00211.1.

Lin, Y., M. Zhao, and M. Zhang, 2015: Tropical cyclone rainfall area controlled by relative sea surface temperature. Nat. Commun., 6, 6591, https://doi.org/10.1038/ncomms7591.

Maclay, K. S., M. DeMaria, and T. H. Vonder Haar, 2008: Tropical cyclone inner-core kinetic energy evolution. Mon. Wea. Rev., 136, 4882-4898, https://doi.org/10.1175/2008MWR2268.1.

Meissner, T., and F. J. Wentz, 2012: The emissivity of the ocean surface between 6 and $90 \mathrm{GHz}$ over a large range of wind speeds and Earth incidence angles. IEEE Trans. Geosci. Remote Sens., 50, 3004-3026, https://doi.org/10.1109/TGRS.2011.2179662.

—, L. Ricciardulli, and F. J. Wentz, 2017: Capability of the SMAP mission to measure ocean surface winds in storms. Bull. Amer. Meteor. Soc., 98, 1660-1677, https://doi.org/10.1175/ BAMS-D-16-0052.1.

Miller, R. J., A. J. Schrader, C. R. Sampson, and T. L. Tsui, 1990: The Automated Tropical Cyclone Forecasting System (ATCF). Wea. Forecasting, 5, 653-660, http://doi.org/10.1175/ 1520-0434(1990)005\%3C0653:TATCFS\%3E2.0.CO;2.

Morris, M., and C. S. Ruf, 2017: Determining tropical cyclone surface wind speed structure and intensity with the CYGNSS satellite constellation. J. Appl. Meteor. Climatol., 56, 1847-1865, https:// doi.org/10.1175/JAMC-D-16-0375.1.

Mouche, A., B. Chapron, J. Knaff, Y. Zhao, B. Zhang, and C. Combot, 2019: Copolarized and cross-polarized SAR measurements for high-resolution description of major hurricane wind structures: Application to Irma category 5 hurricane. J. Geophys. Res. Oceans, 124, 3905-3922, https://doi.org/10.1029/2019JC015056.

,-- B. Zhang, and R. Husson, 2017: Combined co- and cross-polarized SAR measurements under extreme wind conditions. IEEE Trans. Geosci. Remote Sens., 55, 6746-6755, https://doi.org/10.1109/TGRS.2017.2732508.

Mueller, K. J., M. DeMaria, J. Knaff, J. P. Kossin, and T. H. Vonder Haar, 2006: Objective estimation of tropical cyclone wind structure from infrared satellite data. Wea. Forecasting, 21, 990-1005, https://doi.org/10.1175/WAF955.1.

NHC, 2016: Introduction to storm surge. Storm surge unit, National Hurricane Center. Tech. Rep., 5 pp., https:// www.nhc.noaa.gov/surge/surge_intro.pdf.

Pan, Y., Y.-P. Chen, J.-X. Li, and X.-L. Ding, 2016: Improvement of wind field hindcasts for tropical cyclones. Water Sci. Eng., 9, 58-66, https://doi.org/10.1016/j.wse.2016.02.002.

Powell, M. D., and T. A. Reinhold, 2007: Tropical cyclone destructive potential by integrated kinetic energy. Bull.
Amer. Meteor. Soc., 88, 513-526, https://doi.org/10.1175/ BAMS-88-4-513.

Price, J. F., 1981: Upper ocean response to a hurricane. J. Phys. Oceanogr., 11, 153-175, https://doi.org/10.1175/1520-0485(1981) 011\%3C0153:UORTAH\%3E2.0.CO;2.

Quilfen, Y., B. Chapron, T. Elfouhaily, K. Katsaros, and J. Tournadre, 1998: Observation of tropical cyclones by high-resolution scatterometry. J. Geophys. Res., 103, 7767-7786, https://doi.org/ 10.1029/97JC01911.

Reul, N., B. Chapron, E. Zabolotskikh, C. Donlon, Y. Quilfen, S. Guimbard, and J. Piolle, 2016: A revised L-band radiobrightness sensitivity to extreme winds under tropical cyclones: The five year SMOS-storm database. Remote Sens. Environ., 180, 274-291, https://doi.org/10.1016/j.rse.2016.03.011.

, and Coauthors, 2017: A new generation of tropical cyclone size measurements from space. Bull. Amer. Meteor. Soc., 98, 2367-2385, https://doi.org/10.1175/BAMS-D-15-00291.1.

Rodgers, E. B., and R. F. Adler, 1981: Tropical cyclone rainfall characteristics as determined from a satellite passive microwave radiometer. Mon. Wea. Rev., 109, 506-521, https://doi.org/10.1175/ 1520-0493(1981)109\%3C0506:TCRCAD\%3E2.0.CO;2.

Rogers, R. F., and Coauthors, 2017: Rewriting the tropical record books: The extraordinary intensification of Hurricane Patricia (2015). Bull. Amer. Meteor. Soc., 98, 2091-2112, https:// doi.org/10.1175/BAMS-D-16-0039.1.

Ruf, C. S., and Coauthors, 2016: New ocean winds satellite mission to probe hurricanes and tropical convection. Bull. Amer. Meteor. Soc., 97, 385-395, https://doi.org/10.1175/BAMS-D-14-00218.1.

Sampson, C. R., and A. J. Schrader, 2000: The automated tropical cyclone forecasting system (version 3.2). Bull. Amer. Meteor. Soc., 81, 1231-1240, https://doi.org/10.1175/1520-0477(2000) 081\%3C1231:TATCFS\%3E2.3.CO;2.

—_, P. A. Wittmann, and H. L. Tolman, 2010: Consistent tropical cyclone wind and wave forecasts for the U.S. Navy. Wea. Forecasting, 25, 1293-1306, https://doi.org/10.1175/ 2010WAF2222376.1.

_, E. M. Fukada, J. A. Knaff, B. R. Strahl, M. J. Brennan, and T. Marchok, 2017: Tropical cyclone gale wind radii estimates for the western North Pacific. Wea. Forecasting, 32, 1029-1040, https://doi.org/10.1175/WAF-D-16-0196.1.

— J. S. Goerss, J. A. Knaff, B. R. Strahl, E. M. Fukada, and E. A. Serra, 2018: Tropical cyclone gale wind radii estimates, forecasts, and error forecasts for the western North Pacific. Wea. Forecasting, 33, 1081-1092, https://doi.org/10.1175/WAF-D-17-0153.1.

Sapp, J., S. Alsweiss, Z. Jelenak, P. Chang, and J. Carswell, 2019: Stepped frequency microwave radiometer wind-speed retrieval improvements. Remote Sens., 11, 214, https://doi.org/ 10.3390/rs11030214.

Sitkowski, M., J. P. Kossin, and C. M. Rozoff, 2011: Intensity and structure changes during hurricane eyewall replacement cycles. Mon. Wea. Rev., 139, 3829-3847, https://doi.org/10.1175/ MWR-D-11-00034.1.

Torn, R. D., and C. Snyder, 2012: Uncertainty of tropical cyclone best-track information. Wea. Forecasting, 27, 715-729, https:// doi.org/10.1175/WAF-D-11-00085.1.

Uhlhorn, E. W., and P. G. Black, 2003: Verification of remotely sensed sea surface winds in hurricanes. J. Atmos. Oceanic Technol., 20, 99-116, https://doi.org/10.1175/1520-0426(2003) 020\%3C0099:VORSSS\%3E2.0.CO;2.

,-- J. L. Franklin, M. Goodberlet, J. Carswell, and A. S. Goldstein, 2007: Hurricane surface wind measurements from an operational stepped frequency microwave radiometer. Mon. Wea. Rev., 135, 3070-3085, https://doi.org/10.1175/MWR3454.1. 
Vachon, P. W., and J. Wolfe, 2011: C-band cross-polarization wind speed retrieval. IEEE Geosci. Remote Sens. Lett., 8, 456-459, https://doi.org/10.1109/LGRS.2010.2085417.

Velden, C., and D. Herndon, 2020: A consensus approach for estimating tropical cyclone intensity from meteorological satellites: SATCON. Wea. Forecasting, 35, 1645-1662, https:// doi.org/10.1175/WAF-D-20-0015.1.

- and Coauthors, 2006: The Dvorak tropical cyclone intensity estimation technique: A satellite-based method that has endured for over 30 years. Bull. Amer. Meteor. Soc., 87, 1195-1210, https://doi.org/10.1175/BAMS-87-9-1195.

— , T. Olander, D. Herndon, and J. P. Kossin, 2017: Reprocessing the most intense historical tropical cyclones in the satellite era using the advanced Dvorak technique. Mon. Wea. Rev., 145, 971-983, https://doi.org/10.1175/MWR-D-16-0312.1.

Vigh, J. L., J. A. Knaff, and W. H. Schubert, 2012: A climatology of hurricane eye formation. Mon. Wea. Rev., 140, 1405-1426, https://doi.org/10.1175/MWR-D-11-00108.1.

Vincent, E. M., M. Lengaigne, G. Madec, J. Vialard, G. Samson, N. C. Jourdain, C. E. Menkes, and S. Jullien, 2012: Processes setting the characteristics of sea surface cooling induced by tropical cyclones. J. Geophys. Res., 117, C02020, https:// doi.org/10.1029/2011JC007396.

Willoughby, H. E., and M. E. Rahn, 2004: Parametric representation of the primary hurricane vortex. Part I: Observations and evaluation of the Holland (1980) model. Mon. Wea. Rev., 132, 3033-3048, https://doi.org/10.1175/MWR2831.1.

Wimmers, A. J., and C. S. Velden, 2007: MIMIC: A new approach to visualizing satellite microwave imagery of tropical cyclones. Bull. Amer. Meteor. Soc., 88, 1187-1196, https://doi.org/10.1175/ BAMS-88-8-1187.
— , and — 2016: Advancements in objective multisatellite tropical cyclone center fixing. J. Appl. Meteor. Climatol., 55, 197-212, https://doi.org/10.1175/JAMC-D-15-0098.1.

Wood, V. T., L. W. White, H. E. Willoughby, and D. P. Jorgensen, 2013: A new parametric tropical cyclone tangential wind profile model. Mon. Wea. Rev., 141, 1884-1909, https://doi.org/ 10.1175/MWR-D-12-00115.1.

Wu, C.-C., G.-Y. Lien, J.-H. Chen, and F. Zhang, 2010: Assimilation of tropical cyclone track and structure based on the ensemble Kalman filter (EnKF). J. Atmos. Sci., 67, 3806-3822, https:// doi.org/10.1175/2010JAS3444.1.

$\mathrm{Xu}$, J., and Y. Wang, 2015: A statistical analysis on the dependence of tropical cyclone intensification rate on the storm intensity and size in the North Atlantic. Wea. Forecasting, 30, 692-701, https://doi.org/10.1175/WAF-D-14-00141.1.

Young, I. R., A. V. Babanin, and S. Zieger, 2013: The decay rate of ocean swell observed by altimeter. J. Phys. Oceanogr., 43, 2322-2333, https://doi.org/10.1175/JPO-D-13-083.1.

Zhang, B., and W. Perrie, 2012: Cross-polarized synthetic aperture radar: A new potential measurement technique for hurricanes. Bull. Amer. Meteor. Soc., 93, 531-541, https://doi.org/10.1175/ BAMS-D-11-00001.1.

, - P. W. Vachon, X. Li, W. G. Pichel, J. Guo, and Y. He, 2012: Ocean vector winds retrieval from C-band fully polarimetric SAR measurements. IEEE Trans. Geosci. Remote Sens., 50, 4252-4261, https://doi.org/10.1109/TGRS.2012.2194157.

Zhao, Y., A. A. Mouche, B. Chapron, and N. Reul, 2018: Direct comparison between active $\mathrm{C}$-band radar and passive L-band radiometer measurements: Extreme event cases. IEEE Geosci. Remote Sens. Lett., 15, 897-901, https:// doi.org/10.1109/LGRS.2018.2811712. 